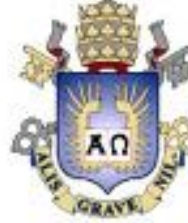

Eveline Libânio Zidan

\begin{abstract}
Análise econômica de projetos de exploração e produção de petróleo com unitização através do uso de opções reais
\end{abstract}

Dissertação de Mestrado

Dissertação apresentada como requisito parcial para obtenção do grau de Mestre pelo Programa de PósGraduação em Engenharia de Produção do Departamento de Engenharia Industrial da PUC-Rio.

Orientador: Prof. Luiz Eduardo Teixeira Brandão 
Eveline Libânio Zidan

\section{Análise econômica de projetos de exploração e produção de petróleo com unitização através do uso de opções reais}

Dissertação apresentada como requisito parcial para obtenção do grau de Mestre pelo Programa de Pós-Graduação em Engenharia de Produção da PUC-Rio. Aprovada pela Comissão Examinadora abaixo.

Prof. Luiz Eduardo Teixeira Brandão

Orientador

Departamento de Engenharia Industrial - PUC-Rio

Prof. Marco Antonio Guimarães Dias

Departamento de Engenharia Elétrica - PUC-Rio

Prof. Davi Michel Valladão

Departamento de Engenharia Industrial - PUC-Rio

Prof. Carlos de Lamare Bastian Pinto

Professor Autônomo

Rio de Janeiro, 12 de Setembro de 2019 
Todos os direitos reservados. É proibida a reprodução total ou parcial do trabalho sem autorização da universidade, do autor e do orientador.

\section{Eveline Libânio Zidan}

Eveline Libânio Zidan graduou-se em Engenharia de Produção em 2007 pela Universidade do Estado do Rio de Janeiro (UERJ), cursou MBA em Finanças pela IBMEC e Pós-Graduação em Engenharia de Petróleo pela PUC-Rio. Aluna de mestrado da PUC-Rio desde março de 2017. Atua na área de Projetos de Desenvolvimento da Produção em empresa na área de Óleo e Gás.

Ficha Catalográfica

Zidan, Eveline Libânio

Análise econômica de projetos de exploração e produção de petróleo com unitização através do uso de opções reais / Eveline Libânio Zidan ; orientador: Luiz Eduardo Teixeira Brandão. - 2019.

84 f. : il. color. ; $30 \mathrm{~cm}$

Dissertação (mestrado)-Pontifícia Universidade Católica do Rio de Janeiro, Departamento de Engenharia Industrial, 2019.

Inclui bibliografia

1. Engenharia Industrial - Teses. 2. Opções reais. 3. Valor da informação. 4. E\&P. 5. Indústria do petróleo. 6. Unitização. I. Brandão, Luiz Eduardo. II. Pontifícia Universidade Católica do Rio de Janeiro. Departamento de Engenharia Industrial. III. Título. 
Ao Marcos José I. P. Bianchessi que nos deixou uma semana antes da minha defesa e foi meu maior incentivador no início da minha na carreira profissional. 


\section{Agradecimentos}

Agradeço aos meus pais, Edilson e Maria Helena, que me proporcionaram todas as oportunidades ao longo da vida para que eu crescesse profissionalmente. Sem eles eu jamais chegaria a este ponto.

À minha irmã, que mesmo de longe, serviu de exemplo para mim, estudando e lutando sempre pelos seus maiores sonhos.

Aos meus amigos que sempre me apoiaram e compreenderam minha ausência para que eu pudesse me dedicar a este projeto. Foi um período muito difícil que precisei de muito incentivo.

À minha amiga Thailine que está ao meu lado em todos os momentos da minha vida e, com o mestrado, não foi diferente. Sem dúvidas foi minha maior incentivadora, não me deixando desistir. Obrigada por tudo, obrigada por fazer parte da minha vida.

À Petrobras e, em especial, ao meu chefe Fernando Maurício de Aquino Mendes por me permitir cursar este mestrado, de forma a conciliar a vida acadêmica com a profissional.

Ao meu professor orientador Luiz Eduardo Teixeira Brandão e ao professor Marco Antônio Dias por todos as orientações e os ensinamentos passados, buscando garantir o prazo e a qualidade deste trabalho.

À PUC-Rio pela oportunidade que me deu de estudar em uma excelente instituição e ter em contato com o mundo acadêmico, passo novo e desafiador na minha vida.

À coordenação do curso, em especial ao professor Davi Michel Valladão, que participou de grande parte dessa reta final, me ensinando e apoiando na conclusão do curso.

O presente trabalho foi realizado com apoio da Coordenação de Aperfeiçoamen de Pessoal de Nível Superior - Brasil (CAPES) - Código de Financiamento 001. 


\section{Resumo}

Zidan, Eveline Libânio; Brandão, Luiz Eduardo Teixeira (Orientador). Análise econômica de projetos de exploração e produção de petróleo com unitização através do uso de opções reais. Rio de Janeiro, 2019. 84 p. Dissertação de Mestrado - Departamento de Engenharia Industrial, Pontifícia Universidade Católica do Rio de Janeiro.

Este trabalho tem por objetivo analisar um projeto de exploração e produção de petróleo típico do pré-sal brasileiro em processo de unitização que possui incertezas técnicas e de mercado e flexibilidade gerencial para adiar o investimento. Esse tipo de projeto, na maioria das empresas, é valorado através dos métodos tradicionais de análise econômica financeira. Já se sabe, no entanto, que quando se tem incertezas e flexibilidade gerencial, existem opções associadas, que tem o potencial de aumentar o valor dos ativos. Foi realizada uma aplicação numérica a um campo de petróleo hipotético através da metodologia de opções reais utilizando dados típicos da indústria. Foi avaliada a alternativa de adquirir informação de reservatório através da realização de um teste de longa duração (TLD), com intuito de reduzir as incertezas técnicas antes da unitização e elaboração do plano de desenvolvimento do campo. Considerando a opção de postergar o investimento no projeto para a realização do TLD, foi possível analisar também o impacto da incerteza de mercado que é, neste caso, o preço futuro do petróleo. Os resultados do estudo indicam que, para todas as partes envolvidas, é ótimo esperar e investir em informação antes de fechar o processo de unitização. Como contribuição, esta dissertação propõe a aplicação de um modelo de opções reais que analisa o valor da informação e o momento ótimo de investimento. Com isso foi possível determinar o VPL de um projeto de desenvolvimento da produção de um campo de petróleo que traz o maior retorno para todas as partes envolvidas.

\section{Palavras-chave}

Opções reais; valor da informação; E\&P; indústria do petróleo; unitização. 


\section{Abstract}

Zidan, Eveline Libânio; Brandão, Luiz Eduardo Teixeira (Advisor). Valuation of petroleum exploration and production projects with unitization using real options. Rio de Janeiro, 2019. 84 p. Dissertação de Mestrado - Departamento de Engenharia Industrial, Pontifícia Universidade Católica do Rio de Janeiro.

This paper analyzes a typical pre-salt oil exploration and production project under an unitization process that has technical and market uncertainties and managerial flexibility to defer the investment. This type of project in most companies is valued through traditional methods of economic and financial analysis. It is known, however, that when there are uncertainties and managerial flexibility, there are associated options that have the potential to increase the value of the project. A numerical application to a hypothetical oil field was made using industry-typical data under the real options approach. The alternative of acquiring reservoir information through an extended well test (EWT) was evaluated in order to reduce technical uncertainties before the unitization process and the draw up of the field development plan. Considering the option to defer the investment in order to do the EWT, it was also possible to analyze the impact of the market uncertainty, which in this case are the future oil prices. The results of the study indicate that, for all stakeholders, waiting and investing in information before finalizing the unitization process is optimal. As a contribution, this dissertation proposes the application of a real option model which analyzes the value of information and the optimal investment timing. With this, it was possible to determine the NPV of an oil field development project that provides the highest return to all stakeholders.

\section{Keywords}

Real options; value of information; E\&P; petroleum industry; unitization 


\section{Sumário}

1 Introdução 14

1.1 Contextualização 14

1.2 Objetivo 16

1.3 Estrutura do Trabalho 18

2 Metodologia de Pesquisa 19

2.1 Análise Tradicional 19

2.2 Críticas a Análise Tradicional 20

2.3 Principais Características de uma Decisão de Investimento 22

2.4 Teoria das Opções Reais (TOR) 23

2.5 Tipos de Opções Reais 25

2.6 Breve Histórico de Opções Reais e Opções Reais na Indústria de Petróleo 26

2.7 Incertezas em Projetos de Exploração e Produção 27

2.7.1 Processos Estocásticos 28

2.7.2 Incertezas Técnicas 29

2.7.2.1 Valor da Informação (VDI) 30

2.7.2.2 Restrição de Capacidade por Falta de Informação 31

2.7.3 Incerteza de Mercado 32

2.7.3.1 Movimento Geométrico Browniano (MGB) 32

2.8 Valoração da Opção Real 34

2.8.1 Equação de Black \& Scholes \& Merton 34

2.8.2 Aproximação Analítica de Bjerksund and Stensland 37

2.9 Modelo de Projetos de Desenvolvimento da Produção de Petróleo 40

3 Desenvolvimento de Projetos de Exploração \& Produção de petróleo com Unitização

3.1 Pré-Sal 43

3.2 Projetos de Exploração e Produção de Petróleo 43

3.2.1 Reservatório 45

3.2.2 Poços 46 
3.2.3 Elevação e Escoamento 46

3.2.4 Instalação de Superfície 47

3.3 Unitização 48

4 Estudo de Caso 52

4.1 Caso Estudado 52

4.2 Metodologia do Estudo 53

4.3 Elaboração do Estudo 54

4.4 O Modelo 56

4.5 Premissas do Modelo 58

5 Resultados 64

5.1 Resultados do Caso Base 64

5.2 Análise de Sensibilidade 69

5.2.1 Custo da Informação $\quad 70$

5.2.2 Fator de Restrição $(\mathrm{y}) \quad 71$

5.2.3 Custo Operacional $\quad 72$

5.2.4 Volatilidade 74

5.2.5 Taxa Livre de Risco $\quad 75$

5.2.6 Taxa de Conveniência $\quad 76$

$\begin{array}{lll}\text { 5.2.7 Sensibilidade do } \square \text { VPL } & 77\end{array}$

6 Conclusões 79

Referências bibliográficas $\quad 82$ 


\section{Lista de figuras}

Figura 1 - Possíveis casos para tomada de decisão

Figura 2 - Linha do tempo do desenvolvimento da Teoria das Opções

Reais

Figura 3 - Jazida de petróleo estendendo-se do limite de um bloco ........48

Figura 4 - Localização dos Acordos de Individualização da Produção -

Bacia de Campos

Figura 5 - Localização dos Acordos de Individualização da Produção -

Bacia de Santos.

Figura 6 - Área de Itapu

Figura 7 - Modelo de Fluxo de Caixa Rígido

Figura 8 - Distribuição de probabilidade de ocorrência para a variável

preço futuro do petróleo neutro ao risco

Figura 9 - Distribuição de probabilidade de ocorrência para a variável volume da reserva

Figura 10 - Distribuição de probabilidade de ocorrência para a variável qualidade da reserva

Figura 11 - Distribuição de probabilidade de ocorrência da opção em t=1.

Figura 12 - Distribuição de probabilidade de ocorrência da opção em t=0

Figura 13 - Distribuição de probabilidade de ocorrência da opção em $t=0$ e líquido do custo de investimento em informação.

Figura 14 - Distribuição de probabilidade de ocorrência do VPL sem informação.

Figura 15- Variação do $\triangle \mathrm{VPL}$ em função da variação do custo da informação.

Figura 16 - Variação do $\triangle \mathrm{VPL}$ em função do fator de restrição.

Figura 17- Variação dos VPLs (com e sem informação) em função do custo operacional

Figura 18 - Variação do $\Delta$ VPL em função da volatilidade ........................75

Figura 19 - Variação do $\triangle \mathrm{VPL}$ em função da taxa livre de risco................76

Figura 20 - Variação do $\triangle \mathrm{VPL}$ em função da taxa de conveniência..........77 Figura 21 - Variação do $\triangle \mathrm{VPL}$ em função da variação de cada parâmetro 


\section{Lista de tabelas}

Tabela 1 - Dados de entrada utilizados no modelo ..............................63

Tabela 2 - Comparativo de valores ..................................................69

Tabela 3 - Variação do $\triangle$ VPL (em US\$ MM) com a variação do custo da informação (em US\$ MM)........................................................... 70

Tabela 4 - Variação do $\triangle$ VPL (em US\$ MM) com a variação do fator de restrição................................................................................ 72

Tabela 5 - Variação do $\Delta \mathrm{VPL}$ (em US\$ MM) com a variação do custo

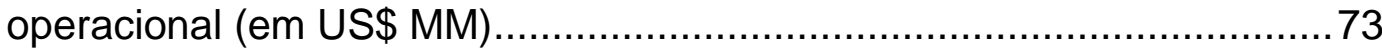

Tabela 6 - Variação do $\Delta$ VPL (em milhões de US\$) com a variação da volatilidade.

.75

Tabela 7 - Variação do $\triangle$ VPL (em US\$ MM) com a variação da taxa livre de risco ........................................................................................ Tabela 8 - Variação do $\Delta$ VPL (em US\$ MM) com a variação da taxa de conveniência 


\section{Glossário}

ADR - Aquisição de Dados de Reservatório

AIP - Acordo de Individualização da Produção

ANP - Agência Nacional de Petróleo, Gás Natural e Biocombustíveis

B\&S\&M - Black \& Sholes \& Merton

CAPM - Capital Asset Pricing Model

CCO - Contrato de Cessão Onerosa

CNPE - Conselho Nacional de Política Energética

EDE - Equação Diferencial Estocástica

EDP - Equação Diferencial Parcial

E\&P - Exploração e Produção

FCD - Fluxo de Caixa Descontado

FCR - Fluxo de Caixa Rígido

FPSO - Floating Production Storage and Offloading

FSO - Floating Storage and Offloading

MGB - Movimento Geométrico Browniano

OR - Opção Real

PD - Plano de Desenvolvimento

PEM - Programa Exploratório Mínimo

SMC - Simulação de Monte Carlo

SPA - Sistema de Produção Antecipada

TLD - Teste de Longa Duração

TIR - Taxa Interna de Retorno

TOR - Teoria das Opções Reais

TP - Tract Participation

UEP - Unidade Estacionária de Produção

VBA - Visual Basic for Applications 
VDI - Valor da Informação

VOI - Value of Information

VOIP - Volume de "Oil in Place"

VP - Valor Presente

VPL - Valor Presente Líquido

WTI - West Texas Intermediate 


\section{Introdução}

\subsection{Contextualização}

Em setores intensivos em capital, onde há irreversibilidade dos investimentos, como a indústria de petróleo, a preocupação com redução de incertezas é recorrente. Investir em procedimentos como Teste de Longa Duração (TLD) que traz informações importantes do campo de petróleo, auxilia na tomada de decisão para elaboração do Plano de Desenvolvimento (PD) do projeto. Segundo a Agência Nacional de Petróleo, Gás Natural e Biocombustíveis (ANP), o PD é o principal instrumento de planejamento do desenvolvimento e da produção de um campo de petróleo. Por meio dele, o consórcio informa sua estratégia de desenvolvimento e gerenciamento da produção do campo, que passará a ser de cumprimento obrigatório pelos contratados.

Outra incerteza comum nesta indústria é o preço futuro do petróleo. O preço do petróleo impacta diretamente na receita das empresas desta indústria, e é um fator determinante para a viabilidade do desenvolvimento de um projeto de exploração e produção (E\&P). Como o prazo para desenvolvimento do campo é significativo, o investidor pode optar por postergar a decisão com o objetivo de esperar o melhor momento para o investimento.

Neste trabalho, foi analisado um campo de petróleo típico do pré-sal brasileiro, onde é comum descobrir nas atividades de exploração e produção reservatórios de hidrocarbonetos que se estendem para um ou mais blocos vizinhos. Segundo Braga e David (2018), o polígono do pré-sal é uma área geradora de petróleo e o volume de óleo e gás nesse reservatório compartilhado costuma ser alto. Devido à estrutura geológica desta área, o processo de unitização é uma questão muito provável de ocorrer quando se desenvolve um campo no polígono do pré-sal.

O processo de unitização (ou individualização da produção) envolve a formação de um novo consórcio composto pelas empresas contratadas para explorar 
cada campo da jazida compartilhada. Se faz necessário firmar um acordo de individualização da produção (AIP) com o objetivo de determinar regras, direitos e obrigações de cada uma das partes e o operador da jazida compartilhada. Neste acordo é estabelecida a participação de cada campo na jazida, chamada de "tract participation" (TP). Um dos anexos ao AIP é o PD da jazida compartilhada, onde o novo consórcio se compromete com o projeto de desenvolvimento descrito nele.

A Agência Nacional do Petróleo (ANP) atua como mediadora deste processo com o objetivo de fiscalizar o cumprimento do cronograma de negociações, garantir a otimização da produção da jazida compartilhada e a harmonização dos termos dos contratos de concessão dos campos envolvidos para que não afronte o interesse público, preservando o cumprimento dos compromissos de conteúdo local e de pagamento de royalties e outras participações.

O desenvolvimento ótimo de um projeto de exploração e produção que tenha unitização geralmente demanda a revelação de maiores informações sobre o reservatório, para reduzir as incertezas sobre o volume e a qualidade da reserva, antes de definir sua capacidade de produção. Isso permite obter um VPL otimizado para jazida compartilhada, que traz benefício não só para as partes, como também para o governo que receberá impostos em cima do volume de petróleo produzido. Porém isto implica em postergar o projeto e despender recursos com investimento em informação, tendo assim a necessidade da avaliação do que é mais interessante em termos de retorno para o projeto. Estudar o valor futuro do petróleo também ajuda na definição do melhor momento para investir, contribuindo para a otimização do VPL.

Neste trabalho, foi adotada a metodologia de opções reais. A Teoria das Opções Reais (TOR) cresceu muito nas últimas décadas, sendo amplamente aplicadas nas análises de projetos de investimento. As opções reais utilizam dois conceitos, o conceito financeiro que enfatiza o cálculo do valor da oportunidade de investimento para a avaliação de ativos e o econômico que enfatiza a regra de decisão onde se tem a opção de investir agora ou esperar o próximo período para reavaliar.

A Teoria das Opções Reais é uma metodologia moderna para análise econômica de projetos e decisões de investimento sob incerteza, onde se tem 
flexibilidade gerencial. Uma empresa pode alterar o cenário definido originalmente devido a diversos fatores, como a mudança nos preços, variação na demanda, captação de novas informações, surgimento de novas tecnologias, entre outros.

\subsection{Objetivo}

O objetivo deste trabalho foi de avaliar o melhor momento para desenvolver um projeto de exploração e produção de petróleo, típico do pré-sal brasileiro, com um processo de unitização em andamento, que possui incertezas técnicas e de mercado. Com o intuito de eliminar ou reduzir as incertezas técnicas, existe a possibilidade de esperar e investir em informação para a tomada de decisão.

As incertezas técnicas do problema são relacionadas ao reservatório de um campo de petróleo e a incerteza de mercado é relacionada ao preço futuro do petróleo. A opção de aprendizagem agrega valor ao permitir que as incertezas sejam reduzidas ou sanadas antes do comprometimento de recursos.

Neste trabalho, foi realizado um estudo de caso com intuito de avaliar se o projeto deveria fazer um Plano de Desenvolvimento (PD) do campo e unitizar imediatamente ou se valeria a pena realizar um Teste de Longa Duração (TLD) no campo, que revelaria informações importantes sobre o reservatório de petróleo, para obter o dimensionamento adequado do projeto e, consequentemente, um VPL otimizado. A Figura 1 apresenta os dois possíveis casos. 


\section{Caso sem investimento em informação:}

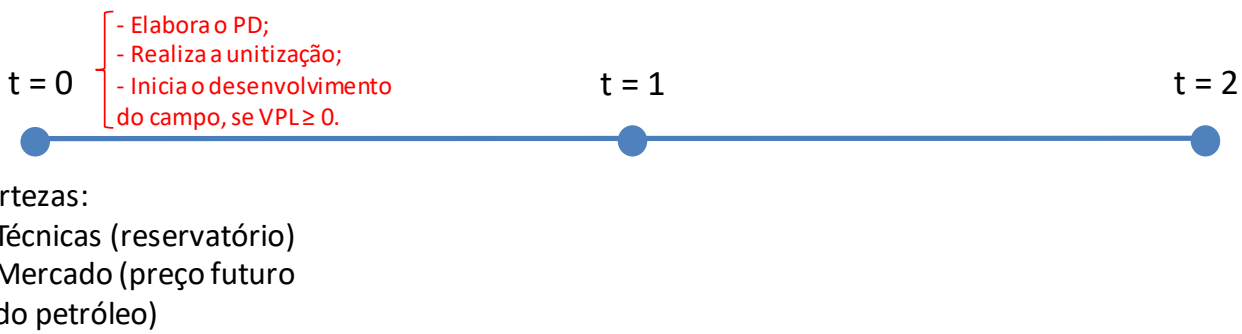

\section{Caso com investimento em informação:}

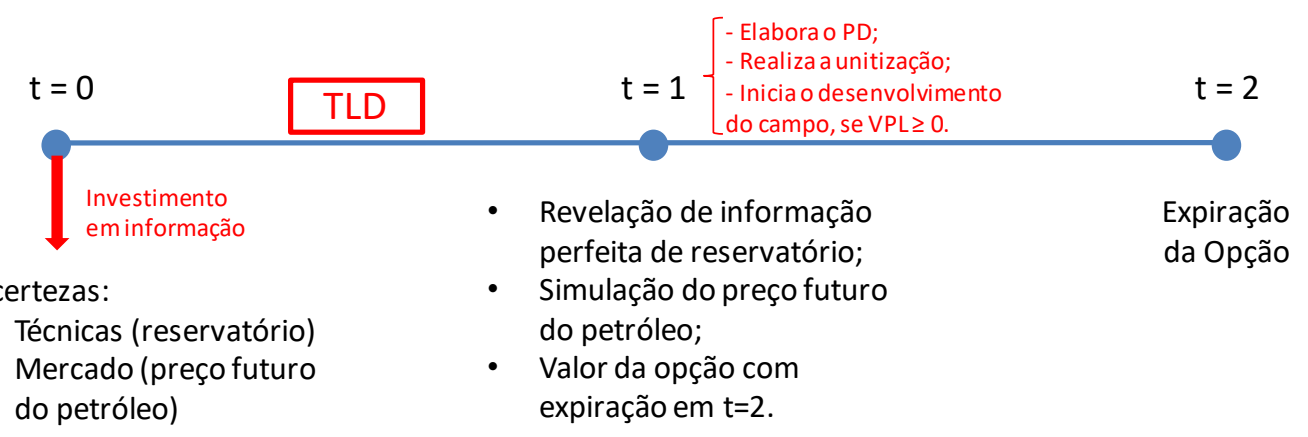

Figura 1 - Possíveis casos para tomada de decisão

Fonte: Elaboração própria

Se após a avaliação entre os dois cenários a decisão ótima seja realizar um Teste de Longa Duração (TLD), o projeto precisa negociar com a Agência Nacional do Petróleo, Gás Natural e Biocombustíveis (ANP) a postergação da entrega do PD e da unitização. Ao realizar o TLD, que leva aproximadamente um ano, o projeto pode ainda observar o comportamento do preço do petróleo. Assim, nesta avaliação, o preço do petróleo também é simulado até o momento da decisão.

No estudo de caso que foi realizado neste trabalho, os resultados indicaram que a revelação de informação endógena e exógena e a opção de realizar ou não o investimento, geram valor ao projeto. Ao postergar a unitização para obter informações relevantes para o desenvolvimento do projeto, obtém-se um valor de projeto (valor da opção real com informação) otimizado que traz benefícios não só às empresas envolvidas, como também ao governo que recebe impostos sobre o volume de petróleo produzido. 
Além do resultado do caso base, foram realizadas análises de sensibilidade com a finalidade de entender como as principais variáveis influenciam, tanto nos resultados, quanto na tomada de decisão. Esta análise mostra que, dependendo dos valores de entrada no modelo, o investimento em informação pode se tornar desinteressante.

\subsection{Estrutura do Trabalho}

Esta dissertação está estruturada em seis capítulos, sendo eles: Introdução, Metodologia, Desenvolvimento de Projetos de Exploração \& Produção com Unitização, Estudo de Caso, Resultados e Conclusões, além das Referências Bibliográficas.

O Capítulo 1 consiste em uma introdução sobre o que foi tratado nesta dissertação, contextualizando e apresentando o objetivo da dissertação.

O Capítulo 2 apresenta a metodologia do trabalho com uma revisão da literatura sobre Teoria das Opções Reais, abordando as incertezas tratadas no estudo de caso desta dissertação.

O Capítulo 3 faz uma apresentação sobre o desenvolvimento de projetos de exploração \& produção de petróleo com unitização.

O Capítulo 4 apresenta o caso estudado de um projeto fictício de petróleo, típico do pré-sal brasileiro, que possui um processo de unitização em andamento, e apresenta incertezas técnicas e de mercado. Neste capítulo, também aborda a elaboração do modelo e premissas utilizadas para simulação do estudo de caso.

O Capítulo 5 mostra os resultados das simulações feitas através do modelo para o caso base e as análises de sensibilidade com a variação de determinados parâmetros do modelo.

O Capítulo 6 finaliza a dissertação com as conclusões do estudo, suas limitações e recomendações para trabalhos futuros. 


\section{Metodologia de Pesquisa}

\subsection{Análise Tradicional}

Dixit e Pindyck (1994) definem investimento como sendo o ato de incorrer em custo imediato na expectativa de recompensas futuras. Segundo Ozorio (2010), a visão tradicional de finanças sobre o investimento nas empresas é a de que somente projetos com expectativa de retorno superior à taxa mínima de atratividade (custo de oportunidade do capital) devem ser investidos.

A análise tradicional de investimentos envolve a avaliação de projetos através da técnica de fluxo de caixa descontado (FCD), da taxa interna de retorno (TIR), da TIR descontada, do método de payback, entre outros. Atualmente, o valor presente líquido (VPL) e a taxa interna de retorno (TIR) são consideradas as ferramentas mais utilizadas na análise de investimento ou seleção de portfólio (Ozorio, 2010).

Para a análise de investimento através do VPL e da TIR, é calculado o fluxo de caixa descontado (FCD), onde são projetados os investimentos e fluxos de caixa futuros esperados para o projeto. Estes são trazidos a valor presente através de uma taxa ajustada ao risco de mercado do projeto. A partir do FCD, o VPL e a TIR são calculados, sendo o primeiro o principal indicador para tomada de decisões.

Em tempo discreto, o VPL é calculado conforme demonstrado abaixo:

$$
V P L=V-I
$$

onde $V$ representa o somatório dos fluxos de caixa operacionais esperados e I o somatório dos investimentos, todos trazidos ao valor presente, ou seja,

$$
V P L=\sum_{t=0}^{T} \frac{E\left[F C_{t}\right]}{(1+k)^{t}}-I
$$

$E\left[F C_{t}\right]$ - valor esperado de cada fluxo de caixa operacional futuro

$k$ - taxa ajustada ao risco 
$t$ - período $\mathrm{t}$

$T$ - número de períodos

Em tempo contínuo, se trabalha com integral, em vez de somatório, e a taxa de desconto é calculada em tempo contínuo.

$$
V P L=\int_{t=0}^{T} e^{-k t} E\left[F C_{t}\right] d t-I
$$

Para tomada de decisão, calcula-se o VPL e caso o mesmo seja positivo, investe, pois há criação de valor. Caso o VPL seja negativo, não investe, pois há destruição de valor. No caso de dois projetos mutuamente excludentes ou no caso de seleção de portfólio, onde os VPL são todos positivos, a empresa escolhe o projeto de maior VPL.

Empresas de petróleo e gás têm a difícil tarefa de seleção portfólio de um grande número de projetos de exploração e produção concorrentes devido a quantidade limitada de recurso financeiro (Lima, 2002). Geralmente há mais oportunidades disponíveis do que capital para investimento. Assim, a técnica do cálculo do VPL dos projetos para seleção de portfólio é amplamente utilizada.

\subsection{Críticas a Análise Tradicional}

A análise tradicional é muito criticada por diversos autores, como Trigeorgis (1993/1996), Dixit e Pindyck (1994), Chorn et al. (1998), Lima (2002) e Ozorio (2010).

Como já citado anteriormente, a técnica para a análise tradicional de investimentos mais utilizada é a avaliação de projetos através do fluxo de caixa descontado (FCD) e, a partir dele, o valor presente líquido (VPL) e a taxa interna de retorno (TIR) são calculados. Apesar de serem métodos de fácil utilização, eles apresentam algumas limitações que veremos a seguir.

Segundo Trigeorgis (1996), uma limitação está relacionada ao fato de que a análise por meio dos métodos tradicionais trabalha com valores estáticos esperados, ignorando as incertezas, colocando o gerente do ativo com um papel passivo, como 
se a única opção fosse realizar o investimento imediatamente e operar o projeto continuamente na forma inicialmente planejada.

Lima (2002) também menciona que os métodos tradicionais baseados no fluxo de caixa descontado relatados na literatura são sempre baseados em suposições estáticas, onde o valor das opções gerenciais não é incorporado. Uma tentativa de enriquecer a tomada de decisão é o uso de taxas mínimas, mas não há um valor teórico claro para aceitar ou rejeitar oportunidades.

Dixit e Pindyck (1994) afirmam que a base de uma análise de investimento de ativos reais são a irreversibilidade, a incerteza e o timing, que são levados em consideração quando se modela uma opção. Estas características não são tratadas pelos métodos tradicionais.

Os métodos tradicionais ignoram o valor da flexibilidade gerencial. Em ativos reais, o gestor tem a opção, e não obrigatoriedade, de investir, além de que a decisão de investir pode ser tomada a qualquer momento. Ignoram, desta forma, a flexibilidade que um gerente pode exercer ao longo do tempo, mudando o caminho inicialmente planejado, no cálculo do valor dos projetos.

Estes métodos tradicionais de avaliação econômica de projetos também não fornecem modelos adequados para a previsão do comportamento futuro das variáveis críticas do projeto, como preços e custos, não analisando assim os possíveis cenários futuros.

Acadêmicos e profissionais reconhecem que a análise tradicional através da técnica de fluxo de caixa descontado (FCD) muitas vezes subvalorizam projetos com opções operacionais reais e outras interações estratégicas. Na prática, muitas empresas ignoram a análise do Valor Presente Líquido (VPL) e usam a intuição para valorar flexibilidade gerencial futura nos ativos (Trigeorgis, 1993).

Ozorio (2010) também aborda casos em que o VPL é positivo e a empresa opta por não investir e vice-versa, reforçando a teoria de que muitos investidores consideram o VPL incapaz de incorporar todos os fatores estratégicos que deveriam ser levados em consideração na tomada de decisão de investimento.

Para o estudo realizado neste trabalho, as ferramentas financeiras tradicionais não seriam as mais adequadas já que não valorizam a flexibilidade 
gerencial. O estudo e aquisição de novos conhecimentos antes de realizar de fato um investimento, permite a mudança de escopo de um projeto sem grandes prejuízos. O uso de FCD para avaliação do valor de um projeto de exploração e produção de petróleo, subestima o impacto do conhecimento incremental do reservatório. Conhecer bem o reservatório permite que se faça um projeto otimizado e que se tome decisões menos arriscadas.

Neste trabalho também foi avaliada uma incerteza de mercado, o preço futuro do petróleo, que as ferramentas financeiras tradicionais não conseguem reproduzir. Conforme Chorn et al. (1998), como consequência, o conhecimento incremental pode ser valorizado por meio de seu impacto na redução do potencial de resultados insatisfatórios do investimento. Assim, a teoria das opções reais surge como uma solução na análise econômica e seleção de portfólio no contexto atual.

\subsection{Principais Características de uma Decisão de Investimento}

Segundo Dixit e Pindyck (1994), a maioria das decisões de investimento apresenta três importantes características em diversos graus. São elas: a irreversibilidade, seja total ou parcial, as incertezas diversas e o grau de liberdade gerencial, especialmente em relação ao timing de investimento.

A irreversibilidade pode ser total ou parcial. Está relacionada a recuperação dos custos já incorridos. Os custos não recuperáveis são chamados de custos afundados ou, em inglês, sunk costs. Quanto maior o grau de irreversibilidade, maior o valor da espera, já que a espera é reversível. Projetos de exploração e produção de petróleo são tipicamente irreversíveis ou pouco reversíveis, como perfuração de poços.

As incertezas são acerca das futuras recompensas pelo investimento. Podem ser encontradas três tipos de incertezas: a incerteza econômica ou de mercado, a incerteza estratégica e a incerteza técnica. Nos projetos de exploração e produção sempre encontramos incertezas econômicas ou de mercado, pois se tem muitas variáveis incertas, como o preço do petróleo, câmbio, demanda, juros, entre outras. As incertezas estratégicas são referentes ao comportamento dos outros agentes, que podem ser outras empresas concorrentes ou outros agentes governamentais. Por 
último, as incertezas técnicas estão sempre presentes nos projetos de exploração e produção de petróleo, como as incertezas de reservatório ou tecnológicas.

O grau de liberdade gerencial pode ser em relação a muitas variáveis. Para análise de projeto, a flexibilidade gerencial em relação ao timing do seu investimento é uma das mais importantes. A maioria dos projetos podem esperar. Poucos são os projetos do tipo "agora ou nunca". Geralmente pode adiar uma decisão até obter mais informações, embora a informação nunca poderá ser completa de modo a eliminar toda a incerteza. No caso de projetos da área de petróleo, existem prazos para a exploração e para a produção, a depender do regime fiscal do campo, mas são prazos suficientemente altos. Dessa forma, é comum a flexibilidade de postergação de um projeto com o objetivo de estudar previamente a área a ser explorada e produzida.

\subsection{Teoria das Opções Reais (TOR)}

Segundo Ma (2016), opções reais vem da teoria das opções financeiras, onde se tem o direito, mas não a obrigação, de investir em ativos físicos, ou seja, conceitos e métodos de opções aplicados em ativos físicos. De acordo com Guedes e Santos (2016), a análise de opções reais precisa capturar as características únicas de projetos individuais e, ao mesmo tempo, permanecer atrativa e intuitiva. Isso é um desafio, uma vez que os projetos reais são muitas vezes complexos, com múltiplas fontes de incerteza, bem como múltiplos investimentos e opções operacionais. Ma (2016) também ressalta que opções reais traz a flexibilidade no gerenciamento, um importante fator nas decisões de investimentos em projeto de exploração de petróleo, pois fornecem ferramentas científicas para valorar estes projetos.

Dixit e Pindyck (1994) aponta as características, já apresentadas neste trabalho, importantes na tomada de decisão de investimentos ou alocação de recursos. São elas: irreversibilidade, incerteza e grau de liberdade gerencial. Estas três características tem impacto no valor de ativos reais, pois permitem entender melhor o valor da opcionalidade e revelação de informação antes de efetivar o investimento. Essa opção tem valor e deve ser considerada ao valorar um projeto. 
$\mathrm{Na}$ indústria de petróleo, a maioria dos investimentos são vistos como irreversíveis. Em uma perfuração de um poço, o gasto com a sonda e equipe para realização da atividade e materiais utilizados não são recuperáveis. Ao final de uma perfuração, no caso de poço seco, o mesmo é abandonado. Dessa forma, a opção de aprendizagem é muito utilizada, onde estudos do reservatório são feitos, antes de efetivar os investimentos. Outra incerteza encontrada na indústria de petróleo é a incerteza de mercado, como a do preço futuro do petróleo, a demanda, câmbio, entre outras. A exploração e desenvolvimento de um campo de petróleo tem prazo suficientemente grande que permite esta espera com objetivo de se obter o melhor momento para o investimento. Como encontramos estas três características nos investimentos desta indústria, claramente temos opções relacionadas às análises econômicas neste tipo de projeto.

Como já mencionado, opções reais é quando se tem o direito, mas não a obrigação, de investir em ativos físicos. A teoria das opções reais procura quantificar esse direito. Quanto maior a incerteza de um projeto, maior o valor agregado da flexibilidade gerencial, aumentando assim o valor das opções relacionadas a ele.

Dixit e Pindyck (1994) definem o valor da oportunidade de investimento, quando se tem flexibilidade, da seguinte forma:

Valor da oportunidade de investimento $=V P L+V P($ valor da opção $)$

Conforme Dias (2014), Opções Reais podem ser vistas como uma otimização sob um problema de incerteza. Na maioria dos casos práticos, se tem como função objetiva típica maximizar o VPL através do gerenciamento ótimo das opções relevantes (flexibilidades gerenciais) sujeito a:

- Incertezas do mercado (preço do petróleo, taxa de sonda, etc.);

- Incertezas técnicas (existência de petróleo, volume e qualidade);

- Restrições legais, éticas, de recursos etc.

Dias (2014) cita como opções relevantes a opção de postergar o investimento (opção de timing), a opção de expandir a produção, a opção de aprendizagem (investimento em informação) e a opção de abandonar. Neste estudo foi analisada a opção de aprendizagem, através da execução de um Teste de Longa Duração (TLD), com o objetivo de obter mais informações do reservatório de um 
campo de petróleo, reduzindo as incertezas técnicas. Aliada à opção de aprendizagem, terá a opção de espera com intuito de esperar por melhores preços de petróleo, que é uma incerteza de mercado.

A Teoria das Opções Reais (TOR), não surgiu para substituir a análise de um projeto através do VPL, mas para acrescentar a flexibilidade gerencial do mundo real, onde se pode decidir o momento certo de iniciar o projeto e até mesmo abandoná-lo ou alterá-lo no meio do caminho. A Teoria das Opções Reais (TOR) faz do VPL o ponto de partida para mostrar um valor que pode ser agregado ao projeto, proporcionando um modo alternativo de avaliação dos projetos.

\section{$2.5 \quad$ Tipos de Opções Reais}

As opções reais surgiram para acrescentar a flexibilidade gerencial na análise econômica, pois ao longo de um projeto novas informações podem surgir fazendo com que o gestor reveja decisões planejadas em resposta a desdobramentos inesperados do mercado. Com a entrada de novas informações e resolução de algumas incertezas, um gestor pode optar por expandir, contrair, abandonar e até modificar um projeto no meio do caminho.

A literatura apresenta diversos tipos de opções reais. Em seu livro, Dias (2014) cita os três tipos de opções reais mais estudados:

- Opção de espera (ou de timing): aguarda o melhor momento para investir, ou seja, se espera uma melhor condição de mercado.

- Opção de expansão ou de crescimento: um projeto é analisado quantitativamente e, se as incertezas técnicas e/ou econômicas se revelarem favorável ao longo da execução do projeto, o mesmo pode ser expandido.

- Opções de parada temporária e de abandono: quando o cenário muda e se torna desfavorável ao projeto, existe a opção de parar temporariamente o projeto, até que o mercado se demonstre favorável novamente, ou, em outros casos, abandonar definitivamente o projeto. 
A literatura não se limita a estes três tipos. Vários autores classificam de formas diferentes. Existem outros tipos de opções como a opção de aprendizagem, quando se estuda, investe em informação e amadurece melhor a ideia do investimento. Além dessa, a opção de troca, opção contratual, entre outras. Neste trabalho, foram estudadas as opções de aprendizagem e a de espera. A primeira se refere às incertezas técnicas de um reservatório de petróleo. A segunda às incertezas de mercado, como o preço futuro do petróleo.

Para o cálculo das opções reais em um projeto, algumas metodologias e técnicas foram sendo estudadas ao longo do tempo. Os próximos itens desenvolverão este assunto.

\subsection{Breve Histórico de Opções Reais e Opções Reais na Indústria de Petróleo}

O conceito de opções iniciou-se na aplicação da valoração de ativos financeiros, onde se tinha o direito de compra ou venda de um ativo financeiro. A partir daí surgiu no mundo corporativo o conceito de opções reais, onde a empresa tem o direito, mas não a obrigação, de investir em um ativo real, seja este um projeto ou uma carteira de projetos de investimento de capital. O termo opções reais veio do fato dessas opções serem de ativos reais e não de um "papel" como os instrumentos financeiros, como era até então aplicada a teoria de opções.

Como já citado anteriormente, o conceito de opções reais surgiu para complementar as análises econômicas já realizadas pelo VPL, capturando os diferentes caminhos que uma empresa pode tomar ao longo da vida do projeto, levando em consideração a flexibilidade gerencial e as incertezas do projeto.

O primeiro autor que citou o termo de opções reais foi o Myers (1977), apesar de Black e Scholes (1973) e Merton (1973) terem sido os pioneiros a desenvolver as ideias quantitativas da Teoria das Opções. Conforme a Figura 2, o tema foi ganhando cada vez mais relevância e vários outros autores apresentaram trabalhos aplicando opções reais. 


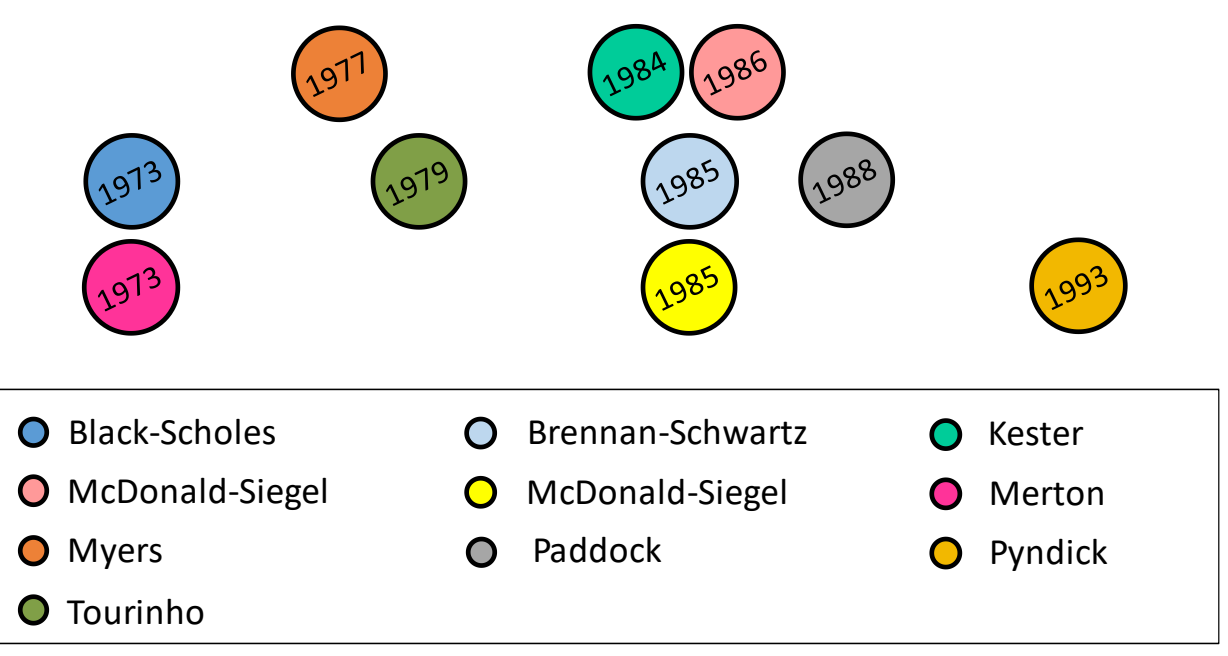

Figura 2 - Linha do tempo do desenvolvimento da Teoria das Opções Reais

Fonte: Adaptado Dezen (2001)

O trabalho de Paddock, Siegel e Smith (1988) é considerado um marco na utilização da Teoria de Opções Reais na indústria do petróleo, sendo o modelo mais popular desta teoria para fazer a valoração das reservas petrolíferas. Neste trabalho foi feito uma analogia entre o valor de uma opção financeira de compra e a opção real sob uma reserva não desenvolvida de petróleo, que pode ser considerada como uma opção de compra de uma reserva desenvolvida de petróleo.

O trabalho de Paddock, Siegel e Smith (1988) deixou claro o motivo dos valores das reservas não desenvolvidas de petróleo praticados pela indústria serem acima dos valores estimados pelos órgãos governamentais, que eram baseados na valoração por VPL.

\subsection{Incertezas em Projetos de Exploração e Produção}

Projetos de exploração e produção de petróleo possuem muitas incertezas inerentes ao negócio. Os principais tipos de incertezas nesta atividade são: as incertezas técnicas, as incertezas econômicas ou de mercado e as incertezas estratégicas. 
As incertezas técnicas são aquelas específicas e, consequentemente, endógenas ao projeto. Incertezas em relação a existência, volume e qualidade de uma reserva de petróleo são exemplos de incertezas técnicas.

As incertezas econômicas ou de mercado são aquelas correlacionadas aos movimentos da economia, exógenas ao projeto. Como exemplo, pode ser citado o preço do petróleo, a demanda de gás, a taxa de câmbio, a taxa de juros, entre outras.

As incertezas estratégicas são relacionadas ao comportamento de outros agentes que interagem no mesmo ambiente econômico. Estas incertezas são endógenas ao projeto e modeladas através da teoria dos jogos. Como exemplo são lances das outras empresas nas rodadas de licitação de áreas da ANP.

Com o objetivo de modelar este estudo, foram definidas três incertezas. As duas primeiras, relacionadas às incertezas técnicas de reservatório, são a qualidade e o volume da reserva. A terceira incerteza é referente ao preço futuro do petróleo (preço médio de longo prazo), que possui variações ao longo do tempo.

Estas incertezas afetam o resultado de um projeto de exploração e produção de petróleo, impactando diretamente no VPL. Estas variáveis podem ser analisadas por processos probabilísticos através da teoria dos processos estocásticos.

\subsubsection{Processos Estocásticos}

Um processo estocástico é um modelo matemático utilizado para estudar um conjunto de variáveis aleatórias que evolui ao longo do tempo de forma pelo menos parcialmente aleatória. Estas variáveis possuem incertezas e podem ser analisadas através de processos probabilísticos. Uma série temporal é considerada uma sequência de observações de uma variável aleatória em intervalos regulares durante um período de tempo, ou seja, a realização de um processo estocástico indexado a intervalos regulares de tempo.

Segundo Dias (1996), um dos processos estocásticos mais utilizados na modelagem do preço futuro do petróleo é o Movimento Geométrico Browniano (MGB) devido à sua simplicidade analítica e, por isso, escolhido para este estudo. 
Já as incertezas técnicas, ou seja, o volume e a qualidade da reserva foram modeladas através da distribuição de probabilidade triangular, onde foram assumidos valores de mínimo, mais provável e de máximo para cada uma das variáveis. Estes parâmetros das distribuições triangulares são estimados por especialistas da empresa de petróleo (geólogos e engenheiros de reservatórios).

Estas variáveis estocásticas foram estudadas através da simulação de Monte Carlo e a função VPL foi parametrizada pelas mesmas. Este método combina as incertezas técnicas (volume e qualidade da reserva) com a incerteza de mercado (preço do petróleo).

\subsubsection{Incertezas Técnicas}

Além de não serem correlacionadas aos movimentos da economia, as incertezas técnicas podem ser reduzidas através do investimento em informações que auxiliam na tomada de decisão.

Conforme Dixit e Pindick (1994), essas opções são chamadas de opções de aprendizagem, pois a empresa busca informação e aprende com esse tipo de investimento, permitindo, por exemplo, um melhor dimensionamento do projeto. Assim, a redução da incerteza técnica cria um benefício adicional, que não é diretamente mensurado pelo fluxo de caixa.

A redução da incerteza técnica tem um papel fundamental na valoração de muitos ativos na área de petróleo. Neste trabalho, foram tratadas duas incertezas técnicas referentes ao reservatório, que são o volume e a qualidade da reserva.

Conforme Dias (2005), como a incerteza técnica independe do risco de mercado, sua correlação com o retorno do portfólio de mercado é nula, fazendo com que o prêmio de risco requerido por investidores diversificados seja zero. Assim, as distribuições de probabilidade das incertezas técnicas não necessitam de nenhum ajustamento ao risco, permanecendo inalteradas, sem a necessidade de ajuste dos processos estocásticos.

Dessa forma, a combinação de incertezas técnicas com incerteza de mercado em modelos de opções reais foi tratada neste estudo utilizando o método neutro ao 
risco. Pode-se usar a taxa livre de risco, nos processos estocásticos neutros ao risco (processos penalizados por um prêmio de risco) das variáveis de mercado, para descontar valores futuros, combinados com as distribuições de probabilidade das incertezas técnicas, que já são naturalmente neutras ao risco.

\subsubsection{Valor da Informação (VDI)}

A análise do valor da informação (VOI - Value Of Information) considera a aquisição de informação para a redução da incerteza. Especificamente, se analisará a redução da variância esperada das distribuições posteriores em um processo sequencial de revelação das expectativas condicionais. Dias (2005) propõe que, quanto maior a redução esperada de incerteza, maior a variância da distribuição de revelações e maior o valor da opção. Distribuição de revelações é a distribuição de expectativas condicionais.

Segundo Yokota \& Thompson (2004), o valor da informação “... avalia o benefício de coletar informação adicional para reduzir ou eliminar incerteza num contexto de tomada de decisão específico".

Coelho e Suslick (2005) definem a análise do valor da informação como sendo essencialmente o cálculo da diferença do valor do ativo com e sem informação. Se o valor da informação for superior ao custo de seu investimento, tal investimento deve ser realizado. Assim, o valor da informação pode ser entendido como o incremento do valor do ativo após o investimento em informação.

Como na indústria do petróleo os investimentos são altos e, na sua maioria, irreversíveis, o estudo adequado do campo antes do comprometimento de recursos é importante para redução das incertezas e otimização do VPL do projeto.

Para revelar o verdadeiro cenário ou, pelo menos, reduzir incertezas técnicas, as empresas de petróleo realizam investimentos em informação de diversas formas. $\mathrm{Na}$ fase exploratória, são feitos investimentos em sísmica 3D e perfuração de poços (pioneiro, estratigráficos, de delimitação, poços em áreas correlacionadas, entre outros). Já na fase de desenvolvimento, as empresas investem em Teste de Longa Duração (TLD) e em outras formas de Aquisição de Dados de Reservatório (ADR). Na fase de produção, as firmas investem em sísmica 4D. 
A importância do VDI vem da possibilidade de usar a informação para otimizar o projeto. Após modelado o problema e rodada a simulação de Monte Carlo, o valor da opção real (OR) com informação terá distribuição contínua resultando em infinitos cenários. A média da distribuição foi usada para comparação do VPL sem a informação.

\subsubsection{Restrição de Capacidade por Falta de Informação}

No estudo realizado nesta dissertação, após calcular o valor da OR com informação e abatido o custo de aquisição da informação, o mesmo foi comparado com o VPL do projeto sem informação para tomar a decisão de investir ou não em informação.

Com o objetivo de encontrar o valor para o VPL sem informação, ou seja, com as incertezas técnicas, se assume que o projeto é otimizado para os cenários esperados do volume e qualidade da reserva $(E[B]$ e $E[q])$.

Quando o volume e a qualidade da reserva real são maiores que os valores esperados, existe uma perda de VPL em função do mal dimensionamento da UEP, ou seja, a UEP escolhida é menor, restringindo a capacidade de produção do campo. Neste caso, o VPL deve ser penalizado pelo chamado fator de restrição $(\gamma)$, que pode ser estimado através de experimentos de reservatório, considerando casos com e sem restrição de capacidade. Este fator de restrição pode assumir valores entre 0 e 1 . Se for 0 , a penalização é máxima, já que a produção potencial a maior nunca será produzida, e se for 1 não há penalização.

Quando o valor do volume e da qualidade da reserva real são exatamente os valores esperados, o VPL do projeto sem informação encontra-se otimizado e não foi gasto nenhum investimento em informação. Este cenário quase certamente não ocorrerá se a distribuição for contínua.

Quando o volume e a qualidade da reserva real são menores que os valores esperados, o projeto vai produzir na sua totalidade, porém o investimento gasto na UEP terá sido maior que o necessário, já que o mesmo é em função do volume esperado da reserva e este foi maior que o volume real.

Nos dois cenários possíveis de acontecer, o VPL sob incerteza é menor que o VPL otimizado com a informação. Porém, quando se investe em informação, o 
desenvolvimento e, consequentemente, retorno do projeto são postergados, além do custo do investimento ser descontado do valor da OR com informação. Por $q$ e $B$ não serem independentes, $E\left[q^{*} B\right] \neq E[q]^{*} E[B]$.

O VPL sem informação, com incerteza técnica, é penalizado na simulação através das equações:

- $\quad$ Se $q^{*} B \leq E[q] * E[B] \rightarrow V P L=q^{*} P * B-I(E[B])$

- $\operatorname{Se} q^{*} B>E[q]^{*} E[B] \rightarrow V P L=\bar{V}+\gamma^{*}(V u, i-\bar{V})-I(E[B])$, sabendo que: $\bar{V}=E[q] * E[B] * P$

Dessa forma, o VPL sem informação foi penalizado devido à incerteza técnica inicial (distribuições a priori de $q$ e $B$ ).

Quando a revelação da informação é imperfeita, o valor da OR com informação também deve ser penalizado, embora com menos intensidade, pois a informação ainda possui incerteza técnica residual, tornando a escolha da UEP após a informação ainda não otimizada.

Por simplicidade, nesta dissertação foi adotada a revelação de informação perfeita, fazendo com que não haja essa penalização por incerteza residual no valor da OR com informação.

\subsubsection{Incerteza de Mercado}

Além das incertezas técnicas, neste trabalho foi estudada uma incerteza de mercado, o preço futuro do petróleo. Como descrito em tópico anterior, a modelagem do preço futuro do petróleo foi feita através do Movimento Geométrico Browniano (MGB), por ser um dos processos estocásticos mais utilizados devido à sua simplicidade analítica.

\subsubsection{Movimento Geométrico Browniano (MGB)}

O Movimento Browniano ou Processo de Wiener é um processo estocástico em tempo contínuo que apresenta três importantes propriedades: 
I. É um processo de Markov em tempo contínuo, onde somente o valor presente da variável é importante para se conhecer seu valor futuro. Os valores históricos são irrelevantes para determinação de sua evolução futura.

II. As mudanças no processo $d z$ para qualquer intervalo de tempo $d t$ são normalmente distribuídas e a variância cresce linearmente com o tempo. $\varepsilon$ segue uma distribuição normal padrão, ou seja, com média zero e desvio padrão um. Assim o valor esperado de $z$ é sempre zero e sua variância é $d t$.

Já que a distribuição de probabilidade da variável depende apenas do seu valor atual, apresenta variações ou incrementos $d z$ independentes num intervalo $d t$ de tempo.

O Movimento Geométrico Browniano (MGB) é um caso do Movimento Browniano ou Processo de Wiener. De acordo com Dixit \& Pindyck (1994), o MGB é usado frequentemente para modelar preços de ações, taxa de juros, taxa salarial, preços de produtos, e outras variáveis econômicas e financeiras. É o processo mais utilizado, já que é uma boa representação para uma grande parte dos ativos, assumindo a premissa que a taxa de variação da variável segue uma distribuição normal com a tendência e a volatilidade do processo constante.

Um processo estocástico x segue um MGB se ele satisfaz a seguinte equação diferencial estocástica (EDE):

$$
d x=\alpha x d t+\sigma x d z
$$

onde:

$\alpha$ - tendência (drift)

$\sigma$ - volatilidade

$d z$ - incremento ou processo de Wiener, onde $d z=\varepsilon \sqrt{d t}$ e $\varepsilon \sim \mathrm{N}(0,1)$

Como neste trabalho foi utilizado um MGB neutro ao risco, então:

$$
d x=(r-\delta) x d t+\sigma x d z
$$

Substituindo $d z=\varepsilon \sqrt{d t}$ : 


$$
d x=(r-\delta) x d t+\sigma x \varepsilon \sqrt{d t}
$$

Para realizar a simulação do processo estocástico, e consequente estimação dos preços futuros, é preciso a equação de discretização, ou seja, ter $X_{t}$ em função de $X_{t-1}$ dado um $\Delta t$. Assim, a solução analítica passa a ser:

$$
X_{t}=X_{t-1} \exp \left[\left((r-\delta)-\frac{\sigma^{2}}{2}\right) \Delta t+\varepsilon \sigma \sqrt{\Delta t}\right]
$$

\subsection{Valoração da Opção Real}

Com o objetivo de valorar uma opção real, deve-se escolher o melhor método a ser aplicado. Como o caso estudado neste trabalho é uma opção real em tempo contínuo, que segue um MGB, foi utilizado o modelo de precificação através da equação diferencial parcial (EDP) de Black \& Sholes \& Merton (B\&S\&M).

\subsubsection{Equação de Black \& Scholes \& Merton}

Este modelo de precificação para um ativo possui as seguintes hipóteses:

1. É possível emprestar e tomar emprestado a uma taxa de juros livre de risco constante e conhecida;

2. O preço segue um MGB com tendência (drift) e volatilidade constantes;

3. Não há custos de transação.

Foi utilizado método dos ativos contingentes, que monta um portfólio sem risco e usa o argumento de não arbitrabem para justificar o uso da taxa livre de risco, para obter a EDP de B\&S\&M. O uso de ativos contingentes requer a premissa de que, quando uma opção real não é transacionada no mercado, seu valor pode ser calculado através de um portfólio de ativos transacionados que replique perfeitamente o retorno do projeto, bem como a volatilidade $\sigma$ e a tendência $\alpha$. Como não há arbitragem, o valor do projeto será exatamente o mesmo que o valor de mercado do portfólio (Brandão, 2002). 
Pelo CAPM, $\mu=r_{f}+\pi$, onde $\mu$ também é a taxa ajustada ao risco exigida pelo investidor de $V$ (valor do projeto), $r_{f}$ é a taxa livre de risco e $\pi$ prêmio de risco. Como o retorno do projeto também é dado pela soma do ganho de capital $\alpha$ com a taxa de dividendo, temos:

$$
\mu=\alpha+\delta=r_{f}+\pi
$$

Para calcular o valor da opção real $F$, é considerado um portfólio $\phi$ dado por uma posição longa e uma posição curta com $n$ unidades do ativo semelhante ou do projeto $V$, onde $n$ é escolhido de forma que o portfólio seja livre de risco.

$$
\phi=F-n V
$$

Num intervalo de tempo $d t$ :

$$
r_{f} \phi d t=r_{f}(F-n V) d t
$$

Sabendo que o retorno do portfólio também pode ser dado como:

$$
r_{f} \phi d t=d F-n(d V+\delta V d t)
$$

onde $d F$ é o retorno da opção (que não paga dividendo) e $(d V+\delta V d t)$ é o retorno do projeto dado pela soma do ganho de capital com os dividendos.

Igualando as duas equações de $\phi$ :

$$
d F-n(d V+\delta V d t)=r_{f}(F-n V) d t
$$

Pelo Lema de Itô:

$$
\begin{gathered}
d F=\frac{\partial F}{\partial V} d V+\frac{\partial F}{\partial t} d t+\frac{1}{2} \frac{\partial^{2} F}{\partial V^{2}} d V^{2} \\
\text { e } \\
d V^{2}=\sigma^{2} V^{2} d t
\end{gathered}
$$

Substituindo as equações acima: 


$$
\left(\frac{\partial F}{\partial V}-n\right) d V+\left[\frac{\partial F}{\partial t}+\frac{1}{2} \frac{\partial^{2} F}{\partial V^{2}} \sigma^{2} V^{2} d t-n \delta V-r_{f}(F-n V)\right] d t=0
$$

Como o portfólio é sem risco, o primeiro termo da Equação 18 deve ser nulo, chegando a $n=\frac{\partial F}{\partial V}$.

Assim, substituindo este valor na equação diferencial, divindo por $d t$ e rearrumando os termos, chega-se na equação diferencial de B\&S\&M:

$$
\frac{1}{2} \frac{\partial^{2} F}{\partial V^{2}} \sigma^{2} V^{2} d t+\left(r_{f}-\delta\right) \frac{\partial F}{\partial V} V+\frac{\partial F}{\partial t}-r_{f} F=0
$$

Esta EDP é genérica e vale para qualquer derivativo que não pague dividendos, para precificar um ativo que segue um MGB e gere dividendos contínuos, podendo ser uma call ou put, americana ou europeia, finita ou perpétua. O que definirá a opção serão as condições de contorno.

As condições de contorno referentes a EDP utilizada neste trabalho estão apresentadas abaixo:

1- Para $V=0, F(0, t)=0$. No processo estocástico, se o valor do projeto valer zero, permanecerá zero e a opção de investir também valerá zero (condição trivial).

2- Para $\mathrm{t}=\mathrm{T}, \mathrm{F}(\mathrm{V}, \mathrm{T})=$ máx $[\mathrm{V}-\mathrm{I}, 0]=$ máx $[\mathrm{VPL}, 0]$. Na data de expiração, se investe se o VPL for positivo.

3- $\mathrm{F}\left(\mathrm{V}^{*}, \mathrm{t}\right)=\mathrm{V}^{*}$-I, sendo $\mathrm{V}^{*} \mathrm{o}$ valor do gatilho (o valor do ativo a partir do qual vale a pena investir) e I o investimento necessário para o projeto (condição de continuidade).

4- $\frac{\partial \mathrm{F}}{\partial \mathrm{V}}\left(\mathrm{V}^{*}, \mathrm{t}\right)=1$. Garante que $\mathrm{F}(\mathrm{V})$ é contínua e tem um contato suave na função VPL de exercício ao redor do ponto de gatilho $\mathrm{V}^{*}$, não havendo outros pontos mais vantajosos para o exercício da opção (condição de contato suave). 
As quatro condições de contorno acima são referentes à opção americana. Para a opção europeia, bastam as duas primeiras, já que as duas últimas são referentes ao exercício antecipado. Aqui se especifica uma opção de compra (call).

A opção americana perpétua possui uma solução analítica já que a EDP vira uma EDO (equação diferencial ordinária) que tem uma solução analítica. Já a opção americana com dividendo, que possui tempo de expiração, não apresenta solução analítica, sendo necessária a utilização de métodos numéricos, como a Simulação de Monte Carlo (SMC), árvores e diferenças finitas (Trigeorgis, 1996) ou aproximações analíticas, como exemplo, a aproximação analítica de Bjerksund e Stensland.

\subsubsection{Aproximação Analítica de Bjerksund and Stensland}

A aproximação analítica proposta por Bjerksund e Stensland (1993) é um dos métodos mais usados para resolver opções americanas com dividendos a uma taxa constante, que possui tempo de expiração.

Bjerksund e Stensland (1993) propõem uma aproximação analítica onde a aproximação da curva de gatilho é representada por uma barreira absorvente superior. Em 2002, os mesmos autores apresentaram um aprimoramento da acurácia da solução analítica anterior, melhorando a aproximação da curva de gatilhos. Como o método de 2002 exige a estimativa da distribuição normal bivariada, o tempo computacional demandado é maior, sendo o ganho de acurácia muito pequeno em relação ao método de 1993 (Dias, 2015). A precisão satisfatória e simplicidade da aproximação analítica de Bjerksund e Stensland de 1993 são os motivos da escolha de seu uso nesta dissertação.

As premissas para o modelo são:

- Modelo de Black \& Sholes \& Merton é assumido;

- Taxa livre de risco positiva $r_{f}$;

- Preço do ativo segue um MGB em relação à medida neutra ao risco;

- Paga dividendo a uma taxa constante $\delta$;

- Possui volatilidade $\sigma$; 
- Mercado é completo, sem oportunidades de arbitragem.

Se a opção é exercida antes da maturidade, ou seja, para $V \geq V^{*}$ :

$$
F(V)=V-I
$$

Caso contrário, para $V<V^{*}$, temos:

$$
\begin{gathered}
F(V)=\alpha V^{\beta}-\alpha \varphi\left(V, T, \beta, V^{*}, V^{*}\right)+\varphi\left(V, T, 1, V^{*}, V^{*}\right)-\varphi\left(V, T, 1, I, V^{*}\right) \\
-I \varphi\left(V, T, 0, V^{*}, V^{*}\right)+I \varphi\left(V, T, 0, I, V^{*}\right)
\end{gathered}
$$

Com:

$$
\begin{gathered}
\alpha=\frac{V^{*}-I}{\left(V^{*}\right)^{-\beta}} \\
\beta=\left(\frac{1}{2}-\frac{r_{f}-\delta}{\sigma^{2}}\right)+\sqrt{\left(\frac{r_{f}-\delta}{\sigma^{2}}-\frac{1}{2}\right)^{2}+\frac{2 r_{f}}{\sigma^{2}}}
\end{gathered}
$$

$\varphi\left(V, T, \gamma, H, V^{*}\right)$

$$
\begin{aligned}
& =e^{\lambda} V^{\gamma}\left\{N\left[-\left(\frac{\ln \left(\frac{V}{H}\right)+\left[r_{f}-\delta+(2 \gamma-1) \frac{\sigma^{2}}{2}\right] T}{\sigma \sqrt{T}}\right)\right]\right. \\
& \left.-\left(\frac{V^{*}}{V}\right)^{K} N\left[-\left(\frac{\ln \left(\frac{V}{H}\right)+\left[r_{f}-\delta+(2 \gamma-1) \frac{\sigma^{2}}{2}\right] T}{\sigma \sqrt{T}}\right)-\frac{2 \ln \left(\frac{V^{*}}{V}\right)}{\sigma \sqrt{T}}\right]\right\}
\end{aligned}
$$

Onde $H \leq V^{*}$, N[.] é a função de distribuição cumulativa normal e:

$$
\lambda=\left[-r_{f}+\gamma\left(r_{f}-\delta\right)+\frac{1}{2} \gamma(\gamma-1) \sigma^{2}\right] T
$$




$$
K=\frac{2\left(r_{f}-\delta\right)}{\sigma^{2}}+(2 \gamma-1)
$$

Assim, o valor de gatilho $V^{*}$ fica:

$$
V^{*}=V_{0}^{*} e^{h}+\left[\left(1-e^{h}\right)\right]
$$

Sendo:

$$
\begin{gathered}
h=-[(r-\delta) T+2 \sigma \sqrt{T}]\left[\frac{V^{*}{ }_{0}}{\left(V^{*}{ }_{\infty}-V^{*}{ }_{0}\right)}\right] \\
V^{*}=\frac{\beta}{\beta-1} I \\
V^{*}{ }_{0}=\operatorname{máx}\left\{I,\left(\frac{r}{\delta}\right) I\right\}
\end{gathered}
$$

Com a estratégia não ótima de adotar um preço de exercício antecipado (gatilho) $V^{*}$, o valor obtido para a opção representa um limite inferior, que pode servir como uma aproximação acurada do verdadeiro valor.

Nesta dissertação foi utilizado um código VBA (Visual Basic for Applications), desenvolvido por Dias (2015), que permite obter o valor da opção americana de compra com a função BjStAmericanCall $(V, I, T, r, \delta, \sigma)$. Esta função permite resolver o problema da opção real composta de exploração e produção de petróleo, em que o preço segue um MGB e a opção tem um tempo finito de expiração. Este código VBA simula uma curva de gatilho até a data de expiração com a simulação de Monte Carlo (SMC), onde se exerce a opção na medida em que vai tocando o ponto de exercício e traz ao valor presente. 


\subsection{Modelo de Projetos de Desenvolvimento da Produção de Petróleo}

Em opções reais, o VPL é o resultado de exercício de uma opção real, ou seja, o payoff de exercício, e é representado com uma função de variáveis-chave onde o preço do produto é o principal fator de risco do projeto.

Dessa forma, Dias (2014) utiliza dois modelos para projetos de desenvolvimento da produção de petróleo, onde o preço do petróleo é o principal fator de incerteza que pode afetar a atratividade do projeto. São chamados de "Modelo de Negócios" e "Fluxo de Caixa Rígido".

O "Modelo de Negócio" assume que o valor da reserva desenvolvida ( $V$ ) é proporcional ao preço do barril de petróleo na superfície $(P)$ e que o fator de proporcionalidade é chamado de qualidade econômica da reserva $(q)$. B é a quantidade de petróleo recuperável economicamente (em barris).

$$
V P L(P ; q, B)=V-I=q B P-I
$$

Tanto o "Modelo de Negócios" quanto o "Fluxo de Caixa Rígido" são modelos lineares que assumem que o valor da reserva desenvolvida é perfeitamente correlacionado com o preço de petróleo. No "Modelo de Negócios" o custo operacional está embutido na qualidade $q$.

A qualidade econômica da reserva pode ser retirada do gráfico VPL x P, onde a inclinação é igual a $q^{*} B$.

Já no "Fluxo de Caixa Rígido", não se assume que o custo operacional é embutido no fator $q$. $\mathrm{O}$ valor presente dos custos operacionais $(C)$ é tratado de forma separada, conforme Equação 32.

$$
V P L\left(P ; q^{\prime}, B, C\right)=V-I=q^{\prime} B P-C-I
$$

Nos dois modelos, P é o preço médio de longo prazo (horizonte da produção do campo) do petróleo. Será usado como proxy o preço do mercado futuro para a entrega em dois anos somado a um prêmio de risco, já que o preço do mercado futuro está na medida neutra ao risco. 
Em ambos os modelos, os valores da qualidade econômica da reserva são obtidos a partir dos VPL calculados em planilhas eletrônicas. A diferença básica entre eles é sintetizada pela inclinação da reta do VPL em função do preço do petróleo. Pelo gráfico VPL x P, pode ser constatado que o "Modelo de Negócios" é menos sensível ao preço que o "Fluxo de Caixa Rígido", já que possui a curva com menor inclinação.

Estes modelos implicam que o valor do ativo $(V)$ segue um MGB com os mesmos parâmetros do preço do petróleo $(P)$. Neste trabalho, foi utilizado o modelo de "Fluxo de Caixa Rígido".

Considerando a neutralidade ao risco, a equação diferencial estocástica (EDE) para o preço do petróleo é dado pelo seguinte MGB neutro ao risco:

$$
d P=(r-\delta) P d t+\sigma P d z
$$

A partir do Lema de Itô sobre $V(P, t)$ :

$$
d V=\frac{1}{2} \frac{d^{2} V}{d P^{2}}(d P)^{2}+\frac{d V}{d P} d P+\frac{d V}{d t} d t
$$

Dado que $V=q^{\prime} B P-C$ :

$$
\frac{d V}{d t}=0 \quad \frac{d V}{d P}=q^{\prime} B \quad \frac{d^{2} V}{d P^{2}}=0
$$

Substituindo:

$$
\begin{gathered}
d V=q^{\prime} B(d P)=q^{\prime} B(r-\delta) P d t+q^{\prime} B \sigma P d z \\
d V=(r-\delta)(V+C) d t+\sigma(V+C) d z
\end{gathered}
$$


Seguindo o modelo de "Fluxo de Caixa Rígido", a EDP para uma opção $F(P, t)$ de um ativo e suas condições de contorno são:

$$
\frac{1}{2} \frac{\partial^{2} F}{\partial P^{2}} \sigma^{2} P^{2} d t+\left(r_{f}-\delta\right) \frac{\partial F}{\partial P} P+\frac{\partial F}{\partial t}-r_{f} F=0
$$

1. $\operatorname{Para} \mathrm{P}=0, \mathrm{~F}(0, \mathrm{t})=0$;

2. Para $\mathrm{t}=\mathrm{T}, \mathrm{F}(\mathrm{P}, \mathrm{T})=$ máx (q'BP-C-I, 0) = máx $[\mathrm{VPL}, 0]$;

3. $\mathrm{F}\left(\mathrm{P}^{*}, \mathrm{t}\right)=\mathrm{q}^{\prime} \mathrm{BP} \mathrm{P}^{*} \mathrm{C}-\mathrm{I}$, sendo $\mathrm{P}^{*} \mathrm{o}$ valor de gatilho;

4. $\frac{\partial \mathrm{F}}{\partial \mathrm{P}}\left(\mathrm{P}^{*}, \mathrm{t}\right)=\mathrm{q}^{\prime} \mathrm{B}$

Com o objetivo de resolver esta EDP, pode-se utilizar a Aproximação Analítica de Bjerksund and Stensland. 


\section{Desenvolvimento de Projetos de Exploração \& Produção de petróleo com Unitização}

\subsection{Pré-Sal}

O pré-sal está entre as maiores descobertas do mundo nos últimos anos. É uma reserva petrolífera localizada abaixo de uma profunda da camada de sal, formando uma das várias camadas rochosas do subsolo marinho. O termo pré-sal vem do fato de ter sido cronologicamente formado antes desta camada de sal. No Brasil, o conjunto de campos petrolíferos do pré-sal situa-se a uns 300 quilômetros da costa, em profundidades aproximadas de 2.000 metros de lâmina d'água e entre 4.000 e 5.000 metros abaixo do fundo do mar. A profundidade total, ou seja, a distância entre a superfície do mar e os reservatórios de petróleo do pré-sal, pode chegar a 7.000 metros.

Em razão de sua profundidade, da complexidade da operação e da necessidade de desenvolvimento de novas tecnologias, os investimentos em exploração e produção do petróleo são altíssimos, além de serem, na sua maioria, irreversíveis. Apesar disso, o pré-sal é composto por grandes acumulações de óleo leve, de excelente qualidade e com alto valor comercial, trazendo retornos elevados para as empresas deste setor. Para desenvolver um projeto deste porte, é importante investir em informação, com o objetivo de reduzir ou até eliminar as incertezas, antes da aplicação de recursos. O caso estudado nesta dissertação foi de um campo típico do pré-sal brasileiro.

\subsection{Projetos de Exploração e Produção de Petróleo}

A ANP realiza rodadas de licitação de blocos de petróleo, onde empresas interessadas na exploração e produção participam, individualmente ou em forma de consórcio, oferecendo, no caso de regime de concessão, um valor de bônus de assinatura e uma proposta de PEM (Programa Exploratório Mínimo). Neste PEM, as empresas propõem a execução das atividades exploratórias mínimas, como 
pesquisas sísmicas, perfuração de poços exploratórios, entre outras. A empresa ou consórcio que apresenta a melhor proposta de acordo com critérios descritos no edital, recebem o direito de explorar aquele bloco com o objetivo de verificar a existência de jazidas comerciais de petróleo e/ou gás natural.

O vencedor da licitação assina um contrato de exploração e produção daquele bloco que estabelece um prazo para o período exploratório e para o período de desenvolvimento e produção.

$\mathrm{Na}$ fase de exploração são desenvolvidas as atividades exploratórias de geologia e geofísica, com o intuito de obter informações da área adquirida, através da aquisição e processamento de dados sísmicos, perfuração e avaliação de poços exploratórios, realização de Testes de Longa Duração (TLD), entre outras, onde obrigatoriamente deve contemplar o cumprimento do PEM acordado com a ANP. Caso se verifique a existência de petróleo e/ou gás natural economicamente viável, é feita a Declaração de Comercialidade, se configurando assim um campo de petróleo. Caso contrário, esta área é devolvida para ANP.

A partir do momento de Declaração de Comercialidade, se inicia a fase de desenvolvimento, seguida da fase de produção.

Na fase de desenvolvimento de um campo de petróleo é feita a avaliação das oportunidades e depois a seleção e definição do projeto básico e executivo. Antes da apresentação do Plano de Desenvolvimento (PD) do campo são realizados mais estudos no reservatório, com a possibilidade de perfuração de mais poços e realização de Sistema de Produção Antecipada (SPA) com o objetivo de obter ainda mais informações do reservatório para poder definir a melhor malha de drenagem, ou seja, a quantidade e localizações dos poços produtores e injetores que maximizam a de recuperação de petróleo do campo. Em seguida, são feitos estudos do arranjo submarino que otimizam as vazões do óleo e minimizam os custos, para então definir a capacidade necessária do FPSO (Floating Production Storage and Offloading) que ficará no campo.

Após a definição do projeto, é apresentado a ANP o PD e feita a implantação do mesmo, com a construção e instalação da plataforma, perfuração e completação dos poços e interligação deles à plataforma. 
O objetivo da produção é explotar o máximo de petróleo de um reservatório, levando em consideração aspectos ambientais e diretrizes de segurança, através da elevação do petróleo pelos poços e escoamento pelas linhas até sua chegada na facilidade de produção na superfície. Ao chegar na plataforma, o petróleo é escoado através de oleoduto ou retirado por meio de navios aliviadores e o gás por gasodutos. Esta etapa é a mais longa de todo o ciclo de vida de um campo de petróleo, podendo se estender por décadas a depender da capacidade produtiva do campo. O fim da produção pode ocorrer pelo fim do prazo contratual ou pela não atratividade econômica do campo.

O desenvolvimento de um projeto de exploração e produção de petróleo envolve quatro diferentes áreas, a saber: reservatório, poços, elevação e escoamento e instalação de superfície. Os próximos tópicos descrevem de maneira sucinta cada uma delas.

\subsubsection{Reservatório}

A área de Reservatórios é considerada uma das mais importantes, principalmente nas primeiras fases de um projeto de desenvolvimento de um campo. É a partir dos seus estudos que todas as outras disciplinas se baseiam. Um bom estudo de reservatório garante um bom projeto.

Os estudos de reservatórios envolvem aquisição sísmica, processamento sísmico, perfuração de poços exploratórios, Testes de Longa Duração (TLD) ou Sistema de Produção Antecipada (SPA), retirada de testemunhos do poço, que são pedações de rocha do reservatório para análise laboratorial, entre outros. Todas essas ferramentas permitem estudos que definem o tamanho do reservatório, o volume de "oil in place" (VOIP), a permeabilidade e a porosidade da rocha, as fraturas e falhas que a rocha apresenta, o contato óleo/água, entre outras características para a análise da sua malha de drenagem.

Segundo Marques (2011), a simulação de reservatório na indústria do petróleo tornou-se uma das ferramentas mais importantes para a solucionar problemas de engenharia de reservatórios. Vários simuladores foram desenvolvidos para analisar os processos de recuperação de óleo. A partir das simulações de 
reservatório, os projetos de desenvolvimento obtêm as curvas de produção com suas probabilidades de ocorrência. Quanto mais próximas estiverem as curvas pessimistas e otimistas, menores são as incertezas em relação ao reservatório.

Cemin, Maliska e Cordazzo (2003) também colocam que a informação de como o reservatório poderá se comportar durante sua explotação é decisiva quanto a localização de poços, injeção de água (em processos de recuperação secundária), tempos de produção, entre outras definições para o projeto. Eles complementam que são esses fatores que determinam a situação produtiva de um reservatório sob o ponto de vista econômico.

Martini et al. (2005) descreve este processo como sendo complexo por envolver uma série de variáveis e na qual se busca a redução de custos, maximização da produtividade e aumento da vida útil do reservatório.

\subsubsection{Poços}

No projeto de desenvolvimento da produção de um campo de petróleo, após os estudos de reservatório, são elaborados os projetos de poço. Os poços podem ser de dois tipos: poços produtores ou poços injetores. Os poços produtores são os poços através do qual é drenado o petróleo do reservatório, sendo levado até a superfície. Já os poços injetores são os que injetam água ou gás dentro do reservatório com o objetivo de pressurizar o reservatório.

Poços é uma das áreas mais importantes em engenharia de petróleo por ser a que representa maior investimento. As atividades de perfuração e completação são realizadas através de sondas, que possuem elevadíssimas taxas diárias de aluguel.

\subsubsection{Elevação e Escoamento}

A disciplina de elevação e escoamento tem o objetivo de otimizar a vazão de petróleo que sai do poço até a plataforma, minimizando os custos através do layout submarino otimizado e da definição dos equipamentos a serem utilizados. 
Silva (2015) descreve um sistema submarino de produção como um "conjunto de todos os equipamentos instalados no leito marinho com a função de permitir e contribuir para o escoamento dos fluidos produzidos até uma unidade de produção". Os equipamentos além de servirem como passagem para os fluidos, controlam a vazão, as pressões e as temperaturas na elevação do petróleo até a superfície e fornece energias elétrica e hidráulica ao sistema para a atuação de válvulas e funcionamento de sensores, por exemplo.

Com a integração de todas as disciplinas, reservatório, poço e elevação e escoamento, é simulada a quantidade de petróleo a ser produzida por ano. Essa quantidade irá determinar a capacidade da plataforma a ser implantada no projeto.

\subsubsection{Instalação de Superfície}

Toda a produção escoada é destinada a uma Unidade Estacionária de Produção (UEP). É nela onde todo o petróleo produzido fica armazenado até ser escoado através de um oleoduto ou levado para terra por navios aliviadores, e todo o gás é enquadrado para ser escoado pelo gasoduto. Grande parte das UEPs possuem sistemas de tratamento e processamento primário para adaptar o fluido à especificação requerida para transporte. A água produzida também é tratada antes de ser descartada ou reinjetada.

Existem diversos tipos de UEP para os projetos offshore. A definição da melhor plataforma vai depender da vazão de produção, capacidade de processamento necessária e lamina d'água. Existem plataformas fixas, semissubmersível, de pernas atirantadas, FSO e navio-plataforma FPSO (unidade flutuante de produção, armazenamento e transferência, que em inglês é “Floating Production Storage and Offloading").

Pelas características do pré-sal, o tipo de UEP mais utilizado é o navioplataforma FPSO. No estudo realizado, foram simulados cenários onde diferentes capacidades de FPSO foram requisitados. Como os custos do FPSO variam de acordo com a capacidade instalada, quanto maior o FPSO, maior o custo. Em compensação, contratar um FPSO abaixo da capacidade irá restringir a produção, limitando o potencial de receita do projeto. 


\subsection{Unitização}

É comum descobrir nas atividades de exploração e produção (E\&P) de petróleo reservatórios de hidrocarbonetos que se estendem para um ou mais blocos vizinhos. Seus limites podem ir além das áreas contratadas nas rodadas de licitação de blocos exploratórios de petróleo e se expandirem além das fronteiras destes blocos, de estados e até mesmo de países, conforme demonstrado na Figura 3.

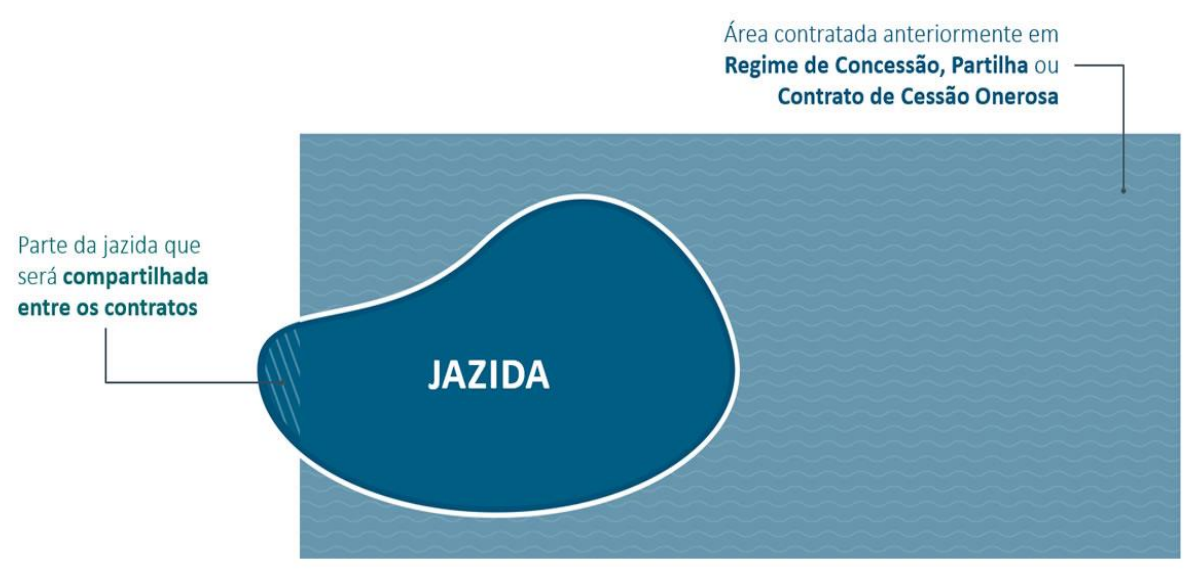

Figura 3 - Jazida de petróleo estendendo-se do limite de um bloco

Fonte: http://www.presalpetroleo.gov.br

Historicamente, a experiência internacional, onde ocorria estes casos de reservatório se estendendo para o bloco vizinho, mostrou a competição entre as empresas para ver quem produzia o petróleo mais rápido, causando danos ao reservatório e redução de sua vida útil.

Egba et al. (2016) discutem que estes reservatórios são a base para a existência da unitização. Para que não haja a produção predatória, as empresas devem firmar um Acordo de Individualização da Produção (AIP) com o objetivo de estabelecer, entre outras coisas, a participação de cada um na produção daquela jazida e quem será o operador do campo, ou seja, o responsável por conduzir as atividades de produção que serão executadas de maneira unificada. Neste acordo são determinadas as regras, permitindo que os custos e receitas sejam compartilhados entre os parceiros desta unitização. O AIP só passa a vigorar após a assinatura das partes e efetivação pela Agência Nacional de Petróleo, Gás e Biocombustíveis (ANP). 
A unitização permite o desenvolvimento de uma jazida compartilhada de forma otimizada no que se refere à racionalidade da produção e à melhoria do fator de recuperação do reservatório. Como resultado, os indicadores econômicos do projeto tendem a ser maximizados. O processo de unitização é um tema em crescimento no Brasil e que está sempre em debate na indústria de petróleo devido à sua complexidade. As Figuras 4 e 5 apresentam as áreas onde já existem Acordos de Individualização da Produção na Bacia de Campos e na Bacia de Santos, respectivamente. Em azul, estão representadas as áreas que já possuem AIPs assinados e, em laranjas, as áreas com AIPs em análise pela ANP.

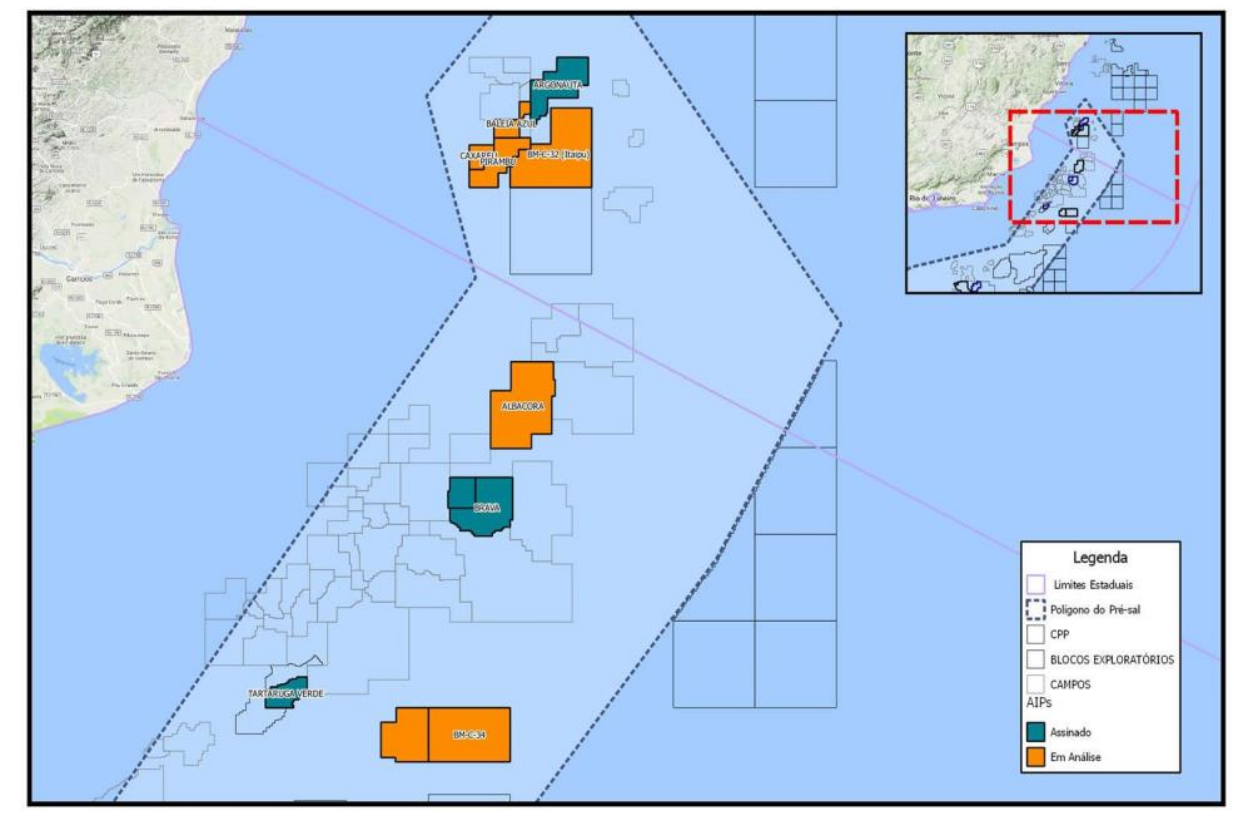

Figura 4 - Localização dos Acordos de Individualização da Produção - Bacia de Campos

Fonte: http://www.presalpetroleo.gov.br 


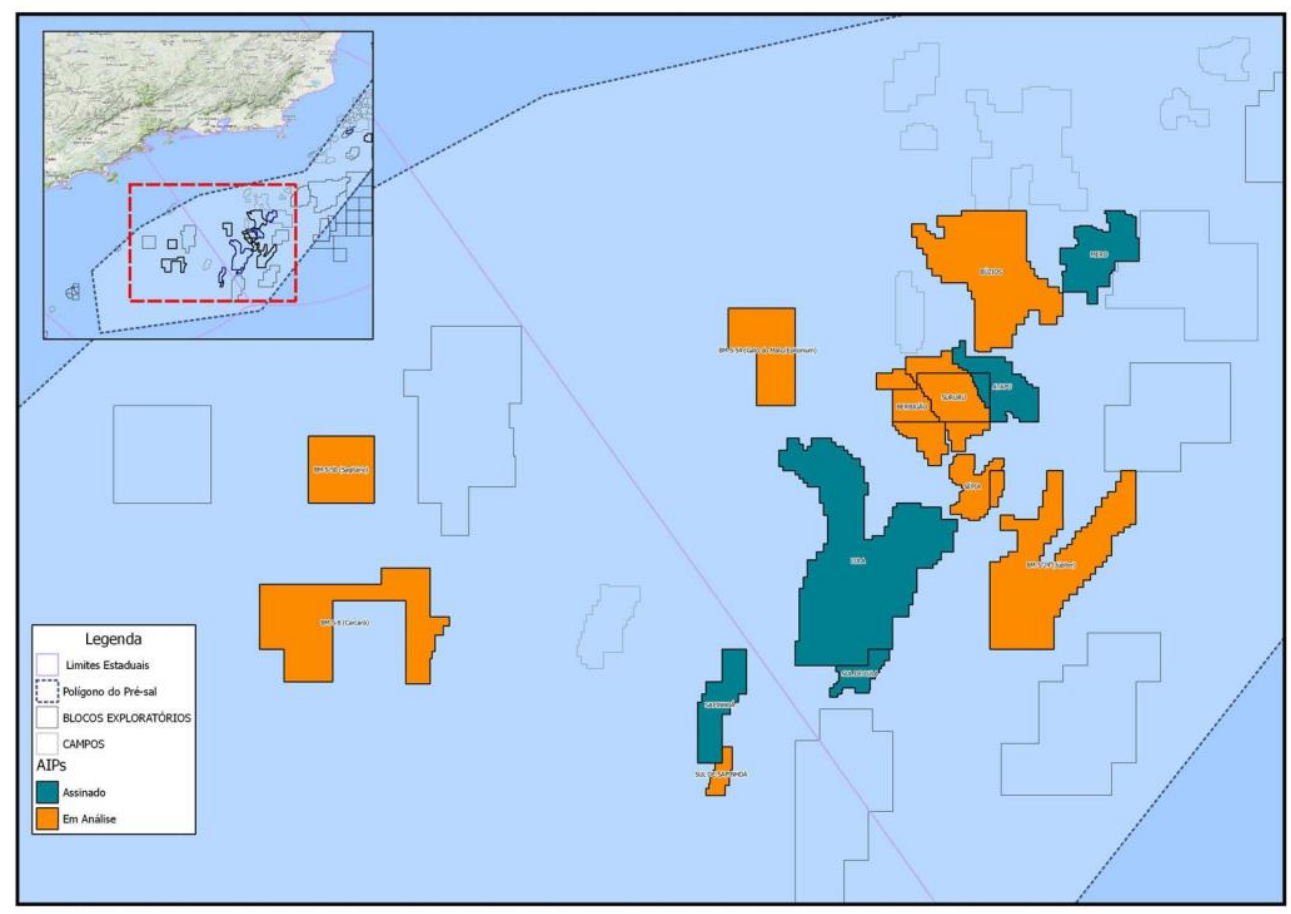

Figura 5 - Localização dos Acordos de Individualização da Produção - Bacia de Santos.

Fonte: http://www.presalpetroleo.gov.br

Conforme Braga e David (2018), Agência Nacional do Petróleo do Brasil (ANP) está prestes a regular os "procedimentos e diretrizes para a negociação do acordo de unitização", de acordo com o artigo 34 da Lei do pré-sal. Em seu trabalho, eles falam sobre a Resolução no 25 de 2013, publicada pela ANP em 9 de julho de 2013, que regula o processo de unitização no Brasil, abrangendo operações onshore e offshore de E\&P. A Resolução 25/2013 da ANP, sobre individualização da produção (unitização), trouxe algumas melhorias para o processo, como regras sobre a definição do operador, divisão dos direitos e obrigações das partes, além das participações nas jazidas compartilhadas.

De acordo com Worthington (2016), a determinação da participação é feita através do cálculo do volume de petróleo no campo abrangendo como um todo, para distribuir subvolumes de petróleo para cada bloco e, a partir desta divisão, determinar as obrigações e direitos das diferentes partes. Na maioria dos AIPs existe a cláusula de redeterminação, onde com um tempo de produção e levantamento de mais informações do reservatório, esta participação pode ser revista para que seja justa a divisão entre as partes. Os custos já incorridos até o momento de redeterminação é equalizado. 
Junto ao AIP o novo consórcio deve enviar o Plano de Desenvolvimento da jazida compartilhada, apresentando o projeto de desenvolvimento da produção. Nesta dissertação foi observado que muitas vezes é necessário negociar a postergação da unitização, ou seja, a entrega do AIP com o PD da jazida compartilhada, com o objetivo de estudar melhor o campo para otimizar o VPL, que traz benefícios não só para as empresas envolvidas, como também para o próprio governo, que arrecada impostos sobre o volume produzido dos campos de petróleo. 


\section{Estudo de Caso}

\subsection{Caso Estudado}

O objetivo proposto neste trabalho foi de avaliar o melhor momento para desenvolver um projeto de exploração e produção de petróleo, típico do pré-sal brasileiro, com um processo de unitização em andamento, que possui incertezas técnicas e de mercado. Com o intuito de eliminar ou reduzir as incertezas, existe a possibilidade de esperar e investir em informação para a tomada de decisão.

Neste estudo de caso, foi analisado um projeto fictício, que possui VPL positivo em $t=0$, porém existe incerteza técnica com relação ao volume e qualidade da reserva. Foi estudada a possibilidade de investir em informação, através da realização de um TLD, com duração de um ano, para revelar informações do reservatório e tomar a decisão a partir do final deste ano, em $t=1$, a depender do cenário revelado, com o objetivo de obter o VPL otimizado para o projeto. Neste cenário, o investimento ocorre entre $t=1$ e $t=2$. Aqui se assume que $t=2$ é a data limite para declaração de comercialidade do campo.

Além da incerteza técnica, existe a incerteza de mercado, em relação ao preço futuro do petróleo. Com esta espera, a empresa observa o comportamento do preço de petróleo com a finalidade de reduzir esta incerteza. A expiração desta opção ocorre em $t=2$. A Figura 1, apresentada no Capítulo de Introdução, mostra os dois possíveis cenários:

1) Em $t=0$ iniciar o desenvolvimento do campo ainda com as incertezas. Isso envolve a elaboração e entrega do PD à ANP e realização da unitização sem investir em informação.

2) Em $t=0$ realizar um TLD com duração de 1 ano e iniciar o desenvolvimento do campo entre $t=1$ e $t=2$. A elaboração e entrega do PD à ANP e realização da unitização seria após o investimento em informação e redução/eliminação de incertezas. Aqui se considera que a expiração da opção é em 
$t=2$. Ou seja, a data limite para declarar a comercialidade e se comprometer com PD é em entre $t=2$, mas pode exercer antes.

Como este projeto está com um processo de unitização em andamento, esperar um ano para tomar a decisão de investimento, com mais informação, pode ser melhor tanto para as empresas envolvidas, que irão fazer o investimento de forma otimizada, quanto para o governo, que recebe tributação proporcional à produção de petróleo.

\subsection{Metodologia do Estudo}

A metodologia adotada neste estudo apresentou os seguintes passos:

1) Definição do problema com o levantamento de dados de projetos similares do pré-sal brasileiro, como a distribuição de probabilidade para o volume e para a qualidade da reserva, o custo operacional e o investimento atualizados, além dos preços de longo prazo do petróleo. Foi necessário também definir outros dados de entrada para o modelo, como a taxa livre de risco, a volatilidade e a taxa de conveniência;

2) Elaboração do modelo aplicando o "Modelo de Fluxo de Caixa Rígido" (FCR). Foi feito o cálculo do VPL do projeto sem investimento em informação, em que é penalizado pela falta da informação, e o valor da OR com informação, através da realização do TLD.

a. Cálculo do VPL sem investimento em informação em $t=0$, penalizado ou pelo fator de restrição, devido a escolha não ótima da UEP para o campo no caso do valor real do volume e qualidade da reserva ser superior ao valor esperado, ou pelo investimento acima do necessário em UEP no caso do valor real ser inferior ao valor esperado.

b. Cálculo do valor da OR do projeto com informação em $t=1$ através das simulações das 3 incertezas do estudo de caso:

- $\quad$ preço do petróleo seguindo um MGB neutro ao risco;

- $\quad$ ' com distribuição de probabilidade triangular;

- $\quad B$ com distribuição de probabilidade triangular. 
O modelo combina estas três incertezas do problema. Este estudo foi feito através da elaboração de cenários de reservatório e de preço de petróleo. A combinação dos cenários de volume e qualidade da reserva e do preço futuro do petróleo foi feita através do método da Simulação de Monte Carlo.

c. Com o objetivo de avaliar o valor da opção em $t=1$, foi aplicada a aproximação analítica de Bjerksund \& Stensland, utilizada em opções americanas de espera de longa duração. Achado o valor, foi trazido para $t=0$ e descontado o valor do investimento em informação para comparação do VPL sem informação em $t=0$.

3) Para tomada de decisão deste estudo de caso, foi feita a comparação entre os dois VPLs, com e sem informação, em $t=0$. Depois foi elaborada uma análise de sensibilidade, alterando determinados parâmetros, com tudo mais constante, para ver o comportamento de cada variável e sua influência na tomada de decisão.

4) Este estudo mostrou que as opções de aprendizagem e de espera, para levantamento de informações técnicas e de mercado, trazem valor ao projeto, pela otimização do VPL. Com a revelação de informação perfeita do reservatório, as empresas podem fazer o projeto de desenvolvimento da produção de forma otimizada. Sendo assim, o melhor para todas as partes interessadas seria postergar a unitização do projeto com o objetivo de entregar um Plano de Desenvolvimento (PD) do projeto com VPL otimizado que trará benefício para todos. O governo também ganha com o projeto otimizado, já que receberá pagamento de royalties e participação especial, que são tributos proporcionais à produção e à rentabilidade do campo de petróleo.

\subsection{Elaboração do Estudo}

No estudo de caso foi elaborado um modelo de simulação para geração de cenários possíveis de reservatório, tanto do volume quanto da qualidade da reserva. Estes valores foram combinados e comparados com os valores esperados, já que sob incerteza, o VPL é otimizado para os cenários esperados. Abaixo estão apresentados os três possíveis cenários: 
- Cenário 1: Quando o volume e a qualidade da reserva real são maiores que os valores esperados, existe uma perda de VPL em função do mal dimensionamento da UEP, ou seja, a UEP escolhida é menor, restringindo a capacidade de produção do campo. Neste caso, o VPL é penalizado pelo chamado fator de restrição $(\gamma)$, que pode ser estimado através de experimentos de reservatório, considerando casos com e sem restrição de capacidade. Este fator de restrição pode assumir valores entre 0 e 1 . Se for 0 , a penalização é máxima, já que a produção potencial a maior nunca será produzida, e se for 1 não há penalização.

- Cenário 2: Ocorre quando o valor do volume e da qualidade da reserva real são exatamente os valores esperados. Este cenário é praticamente impossível de ocorrer. Neste caso, o VPL encontra-se otimizado e não foi gasto nenhum investimento em informação.

- Cenário 3: Quando o volume e qualidade da reserva real são menores que os valores esperados, o projeto vai conseguir produzir na sua totalidade, porém o investimento gasto na UEP terá sido maior que o necessário, já que o mesmo é em função do volume esperado da reserva e este foi maior que o volume real.

Os Cenários 1 e 3, considerados possíveis de ocorrer, possuem VPL sob incerteza menor que o VPL otimizado com a informação. Porém, como o valor da OR otimizado com informação ocorre 1 ano depois, ao trazer para o valor presente para comparação com o VPL sob incerteza, investir em informação pode não ser a decisão ótima.

Além das incertezas técnicas, as empresas de petróleo sofrem muito com as incertezas do mercado. Dentre estas incertezas, o preço do petróleo é uma das que mais afeta a rentabilidade de um projeto.

Para estimar o Fluxo de Caixa Descontado (FDC), as empresas usam como premissa o preço atual, colocando uma pequena tendência, que fica constante a partir de um determinado ano. Esta estimativa geralmente é revisada a cada ano.

Neste estudo, os preços de petróleo relevantes serão os preços de longo prazo do petróleo (e não o preço à vista). Dessa forma, se usou o mercado futuro 
como proxy dos preços de longo prazo para efeito de estimar a volatilidade e estabelecer o preço inicial. Por isso, a volatilidade $(\sigma)$ utilizada nas simulações é mais baixa (efeito Samuelson, ver Dias, 2015) do que a do preço à vista (da ordem de $33 \%$ ), sendo usada uma volatilidade de $20 \%$.

Usualmente se utiliza o preço de mercado futuro, em que se tem uma expectativa neutra ao risco, pois a venda no mercado futuro não tem risco no preço. Este preço tem uma diferença em relação ao preço real, que tem um prêmio de risco. Como referência de longo prazo, é muito comum utilizar o Brent com 12 ou 18 meses ou o WTI com 18 meses. Somado a um prêmio de risco, se tem uma ideia do preço de longo prazo nas atuais estimativas de mercado.

No modelo elaborado neste trabalho, o preço do petróleo é simulado desde $t=0$ até $t=1$, pois o valor da opção é calculado para $t=1$ e trazido a valor presente em $\mathrm{t}=0$ com a taxa livre de risco, momento que foram comparados os dois VPLs, com sem investimento em informação, para tomada de decisão.

Os cenários de volume da reserva, da qualidade da reserva e do preço de petróleo, combinados na simulação de Monte Carlo, apresentam uma curva de probabilidade da opção calculado com a aproximação analítica de Bjerksund \& Stensland. O valor usado para comparação com o VPL sob incerteza foi o valor médio da simulação da opção, trazida ao valor presente e descontada do valor do investimento em informação. $\mathrm{O}$ valor considerado para o investimento em informação foi do custo da realização do TLD. O valor da opção real investindo em informação foi comparado com o VPL do projeto sem informação, realizado em $t=0$, com o preço do petróleo corrente. Este VPL sem informação, quase sempre, não é o VPL otimizado.

\subsection{O Modelo}

Para a modelar o estudo de caso, foi utilizado o software @ Risk, que executa análise de risco através da simulação de Monte Carlo, criando diversos cenários possíveis com suas distribuições de probabilidade. 
Como o estudo de caso apresenta incertezas técnicas e de mercado, foram modelados três parâmetros: o volume da reserva (B), a qualidade da reserva ( $\left.q^{\prime}\right)$ e o preço futuro de petróleo $(P)$.

Para modelar as incertezas técnicas referentes às incertezas do reservatório foi necessário perguntar a um especialista técnico o tipo de distribuição a se considerar. Com as informações levantadas, se teve uma ideia subjetiva das possibilidades de ocorrência por terem sido encontrados os valores de mínimo, mais provável e máximo. Assim, usualmente se aplica a distribuição triangular por ser uma distribuição simples e que resulta em uma boa aproximação das probabilidades de ocorrência. Já a incerteza de mercado foi modelada através de um Movimento Geométrico Browniano (MGB) neutro ao risco, com o objetivo de combinar com as incertezas técnicas.

Os parâmetros $a$ e $b$, da formula de investimento, foram estimados através da regressão linear dos dados levantados, de investimentos e volume de reserva, de um portfólio de projetos do pré-sal com dimensionamento otimizados das UEPs. Assim, o valor de investimento é vinculado ao tamanho da UEP. Se o volume da reserva é conhecido, o sistema de produção, em particular ao tamanho da UEP, pode ser otimizado. Se o tamanho da UEP não estiver otimizado, existem dois casos, o subdimensionamento, onde se produz com restrição de capacidade e o VPL é penalizado através do fator de restrição $(\gamma)$, ou o superdimensionamento, onde foi gasto em UEP acima do necessário.

Sem investir em informação o valor do investimento do projeto é calculado com base no valor esperado de $B: I=a+b * E[B]$. O investimento considerado foi calculado com base no valor esperado, penalizando o VPL. Com informação o investimento é o adequado, $I=a+b(B)$, sem penalização do VPL já que há revelação perfeita do cenário de reservatório, mas terá que trazer o VPL ao valor presente (de $t=1$ para $t=0$ ), além de abater o custo da informação.

Ao rodar as simulações, a cada iteração, o @ Risk amostra valores de $q$ ', $B$ e $P$. Assim, o valor presente do projeto $\left(V=q^{\prime} B P-C\right)$ e o valor do investimento $(I=a+b(B))$ são calculados em cada combinação de cenário. Para calcular o valor da opção, foi utilizada a aproximação analítica de Bjerksund \& Stensland através do código VBA (Visual Basic for Applications), desenvolvido por Dias (2015). 
Como foi utilizado o "Modelo de Fluxo de Caixa Rígido" foi necessário calcular os valores de $V^{\prime}\left(V^{\prime}=V+C\right)$ e $I^{\prime}\left(I^{\prime}=I+C\right)$.

A simulação gera uma curva de probabilidade de $V$ e da opção, onde a opção só é exercida quando o VPL é suficientemente positivo, e trazido para o valor presente pela taxa livre de risco. Para comparar o valor da OR com informação com o VPL sem informação, deve-se abater o custo da informação do valor da OR com informação, que neste caso é o custo do TLD. A decisão a ser tomada será baseada no cenário que trouxer maior valor.

\subsection{Premissas do Modelo}

Com o objetivo de realizar o estudo de caso, premissas foram consideradas para a elaboração do modelo. O caso apresentado é referente a um campo hipotético típico do pré-sal brasileiro e os dados utilizados no modelo são similares à dados de um projeto real. Para isso, foi feito um levantamento de informações de um portfólio de projetos do pré-sal de uma empresa de petróleo com o intuito de se aproximar o máximo possível à realidade.

O modelo calcula o VPL sem investimento em informação e com investimento em informação, através da simulação das variáveis estocásticas e cálculo do valor da opção real. Para a tomada de decisão, estes dois VPLs são comparados.

No caso de não investir em informação, o VPL é penalizado pela falta da informação da qualidade e volume da reserva real. Como já mencionado, quando a reserva real é maior que o valor esperado, o VPL é penalizado por um fator de restrição da capacidade do FPSO $(\gamma)$, que pode ser estimado através de experimentos de simulação de reservatório, considerando casos com e sem restrição de capacidade. São comparados os fluxos de caixa do projeto considerando os valores esperados para o volume e a qualidade da reserva, valores considerados para o dimensionamento, com os fluxos de caixa nos casos onde ficaria subdimensionado e superdimensionado. Este fator depende da diferença entre o valor real e o valor esperado da reserva. Quanto maior for essa diferença, menor será este fator, pois mais subdimensionada estará a capacidade do FPSO. Quando o 
cenário revelado é exatamente o valor esperado, o fator de restrição é igual a 1. Já quando o cenário revelado é menor que o esperado, não há restrição de capacidade, mas sim o excesso. $\mathrm{O}$ excesso de capacidade, no entanto, não aumenta o VPL. O que ocorre é que o VPL também é penalizado por ter sido realizado um investimento no projeto acima do necessário, calculado através do valor esperado do volume da reserva. Algumas simulações de fluxo de caixa com capacidade restringida para casos do pré-sal mostraram que o fator de restrição a ser considerado é de, aproximadamente, 70\%. Dias (2002), em seu trabalho, usou valores próximos a este nos dois casos apresentados (65\% e 75\%) nas simulações numéricas. Análises de sensibilidade foram feitas para esse e outros parâmetros do modelo.

Ao optar por investir em informação, através da realização de um TLD (Teste de Longa Duração) no campo, com duração de um ano, há revelação de informações importantes do reservatório (em $t=1)$, que são a qualidade e o volume da reserva, para a determinação da capacidade ideal do FPSO. Por simplicidade, neste estudo, foi assumida a revelação de informação perfeita dos dados de reservatório. Neste caso, o desenvolvimento do projeto deve ser adiado em pelo menos 1 ano. A produção do TLD reduz o volume da reserva para a etapa de desenvolvimento do projeto. Porém, também por simplicidade, essa redução do volume da reserva não foi considerada no cálculo do VPL com a informação, considerando que o volume da reserva é muito maior que o volume que seria produzido no teste.

As incertezas técnicas do modelo são a qualidade e o volume da reserva. Com o objetivo de atribuir valores hipotéticos ao estudo de caso que representem a realidade, para estimar possíveis valores de volume de reserva, foram utilizadas informações públicas de um campo de pequeno/médio do pré-sal, Itapu. A Figura 6 apresenta a área de Itapu, em que a Petrobras, através do Contrato de Cessão Onerosa (CCO) (Resolução CNPE $n^{\circ} 2$, de $1^{\circ}$ de setembro de 2010), contratou o direito de explotar até 468 milhões de boe. Estimativas do óleo excedente ao CCO, divulgadas pela ANP quatro anos depois, apresentou um volume adicional entre 300 e 500 milhões de boe neste campo (Resolução CNPE $n^{\circ} 1$, de 24 de junho de 2014). Assim, foram utilizados estes valores (volume do CCO mais o volume de óleo excedente), como valor mínimo e máximo e a média deles para o valor mais provável em uma distribuição triangular. 


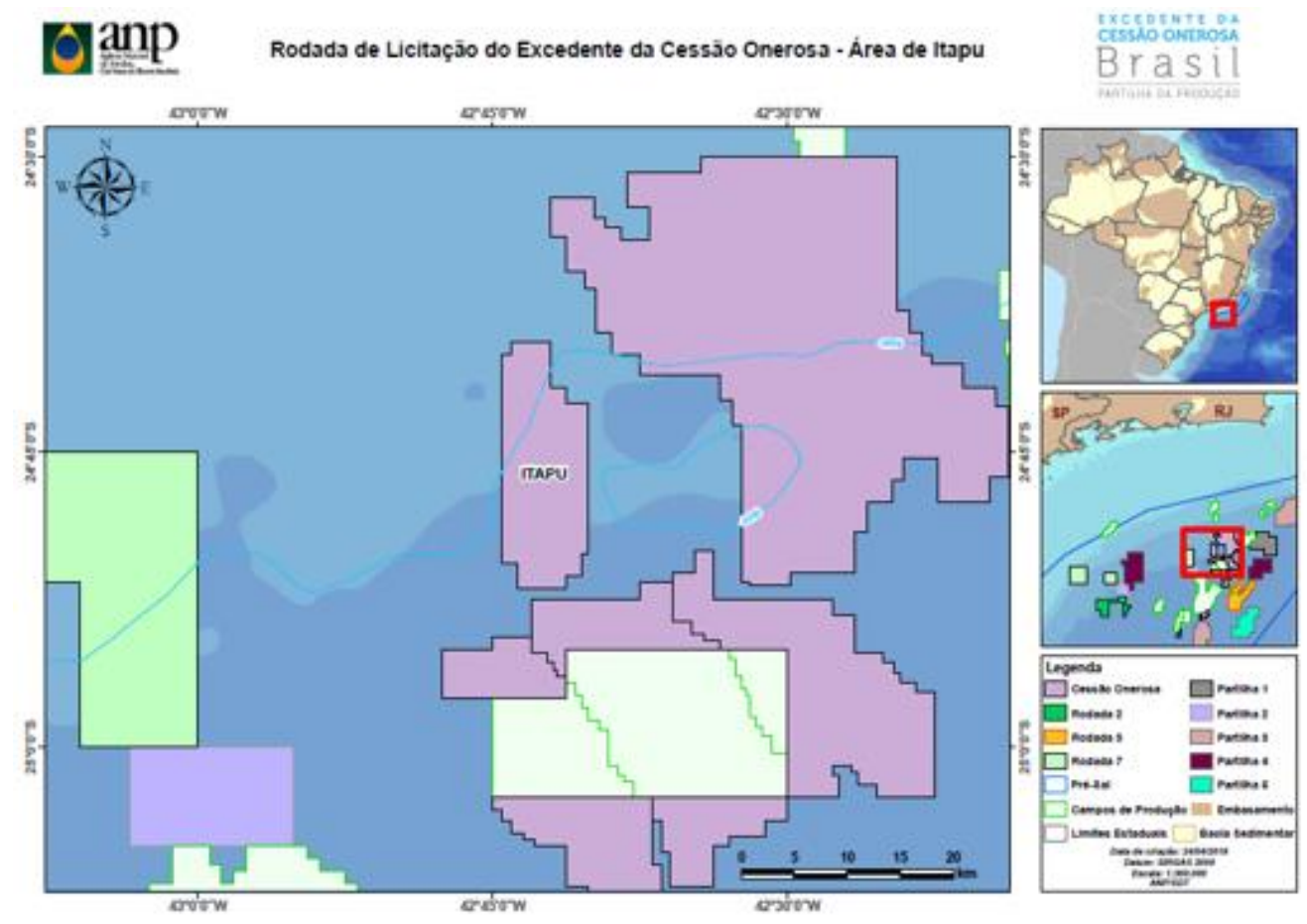

Figura 6 - Área de Itapu

Fonte: http://rodadas.anp.gov.br

Com o levantamento de informações do portfólio de projetos e análises estatísticas, foram atribuídos possíveis valores para a qualidade da reserva de um campo do pré-sal, já que o VPL pode ser considerado linear com o preço do petróleo (Regime de Concessão/Cessão Onerosa). Foi utilizado o gráfico VPL X P do modelo de Fluxo de Caixa Rígido, conforme Figura 7, para fazer este cálculo. 


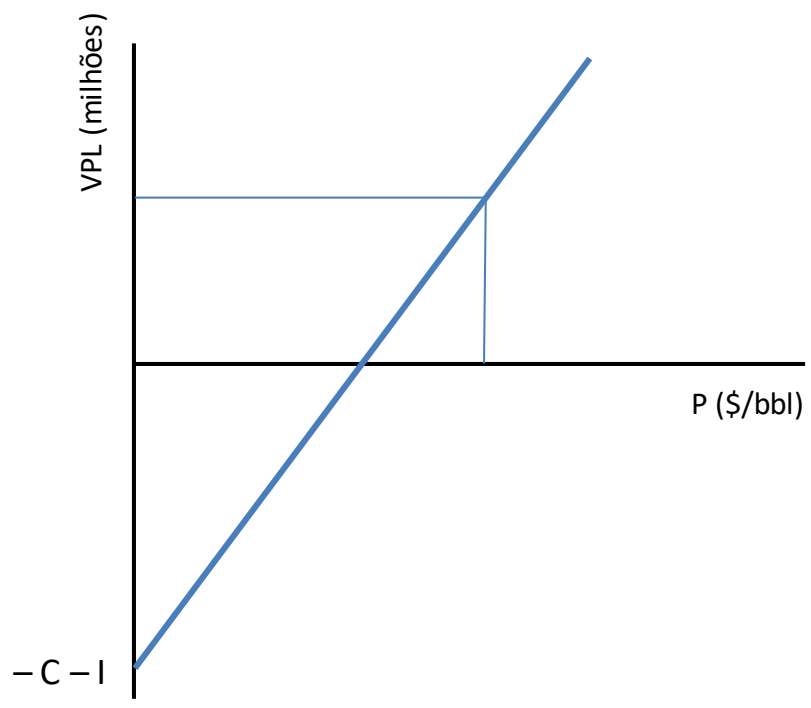

Figura 7 - Modelo de Fluxo de Caixa Rígido

Fonte: Adaptado de Dias (2014)

Os valores assumidos para $q$ ' e $B$ seguem distribuições triangulares com valores de mínimo, mais provável e máximo representados por 6\%, $14 \%$ e $22 \%$ e 768, 868 e 968 milhões de boe, respectivamente.

O preço futuro do petróleo, segue um Movimento Geométrico Browniano (MGB) neutro ao risco, simulado de $t=0$ a $t=1$. Para o cálculo do preço de longo prazo do petróleo foram necessários dados da taxa livre de risco real e taxa de conveniência. Neste estudo foram utilizados os seguintes valores: taxa livre de risco real $\mathrm{r}=3 \%$ a.a. e taxa de conveniência ou taxa de distribuição de dividendos $\delta=$ $3 \%$ a.a.

Atualmente no Brasil o valor nominal da taxa livre de risco está próximo de $6 \%$, ou cerca de $3 \%$ em termos reais, tomando-se como base a taxa Selic e o retorno da NTN-B. A taxa de conveniência $\delta$ pode ser definida e estimada com o mercado futuro, mas por simplicidade usaremos o mesmo valor da taxa livre de risco. Pickles $\&$ Smith (1993), com argumentos de equilíbrio de mercado, sugerem que se use o valor "normal" da taxa de conveniência, como sendo igual à taxa de juros livre de risco, ou seja, fazer $\delta=r$. Foram feitas sensibilidades dos valores desses parâmetros.

Como a receita (e o valor do projeto) se realizará ao longo de vários anos, os preços de petróleo relevantes serão os preços de longo prazo do petróleo (e não 
o preço à vista). O preço inicial do petróleo utilizado na simulação foi o preço no mercado futuro na época do estudo (em $t=0$ para entrega em 18 meses, do petróleo tipo Brent) que é somado a um prêmio de risco. Foi feita uma simulação de um preço de longo prazo, utilizando uma volatilidade baixa de $20 \%$ estimada no mercado futuro do petróleo WTI para entrega em 2 anos. Assim, o preço usado foi de US\$ 60,00 por barril (já ajustado para a qualidade do petróleo do pré-sal).

O valor presente do custo operacional utilizado para o cálculo do VPL do projeto foi de US\$ 1.200 MM. Este valor foi definido através da média aproximada dos valores levantados do portfólio de projetos, com aplicação de um fator de correção para proteger a confidencialidade desses dados. Como premissa do modelo, este valor foi considerado fixo, embora na realidade exista uma parcela fixa e outra variável, que depende do volume produzido.

Para verificar se vale a pena ou não a realização do TLD, foram simulados os cenários de reservatório e preço futuro do petróleo em $t=1$ no @ Risk com 10.000 iterações, obtendo-se assim 10.000 cenários de combinação do preço do petróleo, qualidade e volume da reserva.

Com os valores já mencionados, foi achado o valor presento do projeto $(V)$ neutro ao risco. Para achar o VPL, foi subtraído o valor de investimento do projeto ou custo de desenvolvimento do projeto. No caso de investimento em informação antes de desenvolver, será revelado um volume de reserva $(B)$ com o TLD. Quanto maior a reserva, maior o investimento ótimo para desenvolver o campo. Foi usada uma função linear simples para o investimento ótimo depois da informação, $I(B)$. Essa função investimento (I) possui uma parte fixa (qualquer sistema de produção offshore irá custar algumas centenas de milhões de US\$, independentemente do volume de reserva) ${ }^{1}$ e outra variável, que é em função do valor revelado do volume da reserva. Com a simulação do volume da reserva, foi encontrado o valor ótimo de I. Para estimar os parâmetros dessa função linear, dados de projetos de tamanho similar do pré-sal foram coletados (reserva e investimento), plotados em um gráfico “Investimento Atualizado X Volume da Reserva” e feito uma regressão linear para

\footnotetext{
${ }^{1}$ Caso contrário, se a reserva fosse só de um barril (ou poucos barris), o investimento ótimo seria perto de zero. Mas isso não seria realístico: por menor que seja a reserva, qualquer sistema tem de ter plataforma, poços, dutos de exportação de petróleo, de gás, etc., que custa centenas de milhões de US\$.
} 
encontrar a fórmula de investimento para este tipo de projeto. O coeficiente de determinação $\left(R^{2}\right)$ encontrado foi de 0,97 , ou seja, $97 \%$ dos dados coletados podem ser explicados pela reta de regressão. Como o objetivo era encontrar valores factíveis, no sentido de ordem de grandeza, foi aplicado um fator de correção por não se poder apresentar os valores reais (confidencialidade). Assim, a reta encontrada para o investimento é dada como: $I(B)=400+4^{*}(B)$ (MM US\$).

Com os valores encontrados, foi calculado o valor da opção real, através da aproximação analítica de Bjerksund e Stensland, em $t=1$, que possui expiração de um ano ( $t=2$, um ano depois do TLD). Esta opção pode ser exercida a qualquer momento entre $t=1$ e $t=2$. O valor da opção foi trazido para o valor presente pela taxa livre de risco e descontado o valor do investimento no TLD, ou seja, o custo da informação. Este custo da realização do TLD é líquido de benefícios fiscais. Como foi utilizado dados típicos do pré-sal brasileiro, o valor do custo de um TLD neste tipo de projeto pode ser de aproximadamente US\$100,00 milhões.

Após achado os dois VPLs, com e sem informação, foi feita a comparação entre eles e a decisão ótima de acordo com o que trazia maior retorno. A Tabela 1 apresenta a consolidação dos dados de entrada utilizados no modelo.

Tabela 1 - Dados de entrada utilizados no modelo

\begin{tabular}{|c|c|c|}
\hline Variável & Valor & Unidade \\
\hline$q^{\prime}$ & $\sim$ Triang $(6 ; 14 ; 22)$ & $\%$ \\
\hline$B$ & $\sim$ Triang $(768 ; 868 ; 968)$ & MM boe \\
\hline$P 0$ & 60 & US\$/bbl \\
\hline$r$ & 3 & $\%$ a.a. \\
\hline$\delta$ & 3 & $\%$ a.a. \\
\hline$\sigma$ & 20 & $\%$ a.a. \\
\hline$\gamma$ & 70 & $\%$ \\
\hline CO & 1200,00 & MM US\$ \\
\hline$I$ & $400+4 *(B)$ & MM US\$ \\
\hline CI & 100,00 & MM US\$ \\
\hline
\end{tabular}

Fonte: Elaboração própria 


\section{Resultados}

Este capítulo é composto pelos resultados do caso base descrito acima e, em seguida, pela análise de sensibilidade com a variação de alguns parâmetros. Esta análise mostra como cada um dos parâmetros impactam o resultado.

\subsection{Resultados do Caso Base}

Após rodar a simulação no @ Risk com 10.000 iterações, foi possível observar os resultados do caso base. Primeiro serão apresentados os resultados para o cenário de investir em informação e realizar um Teste de Longa Duração para eliminar as incertezas do reservatório, que são o volume $(B)$ e a qualidade $(q$ ') da reserva. Como isso implica em esperar um período e tomar a decisão em $t=1$, foi realizada também a simulação para a expectativa futura do preço do petróleo neutro ao risco $(P)$ que segue um MGB. Estas três variáveis estocásticas combinadas geram o valor do projeto neutro ao risco. Além disso, a variação do volume da reserva $(B)$, gera variação no valor do investimento.

As figuras 8, 9 e 10 apresentam os gráficos com os resultados das distribuições de probabilidade dos possíveis cenários para o preço do petróleo, volume da reserva e qualidade da reserva. 


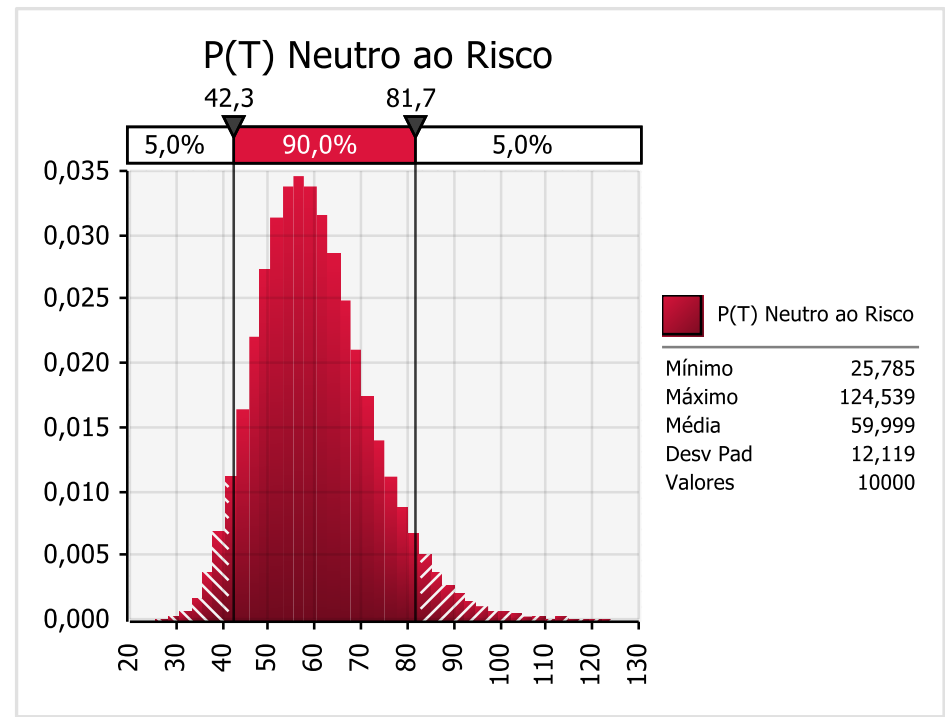

Figura 8 - Distribuição de probabilidade de ocorrência para a variável preço futuro do petróleo neutro ao risco

Fonte: Elaboração própria no @ Risk

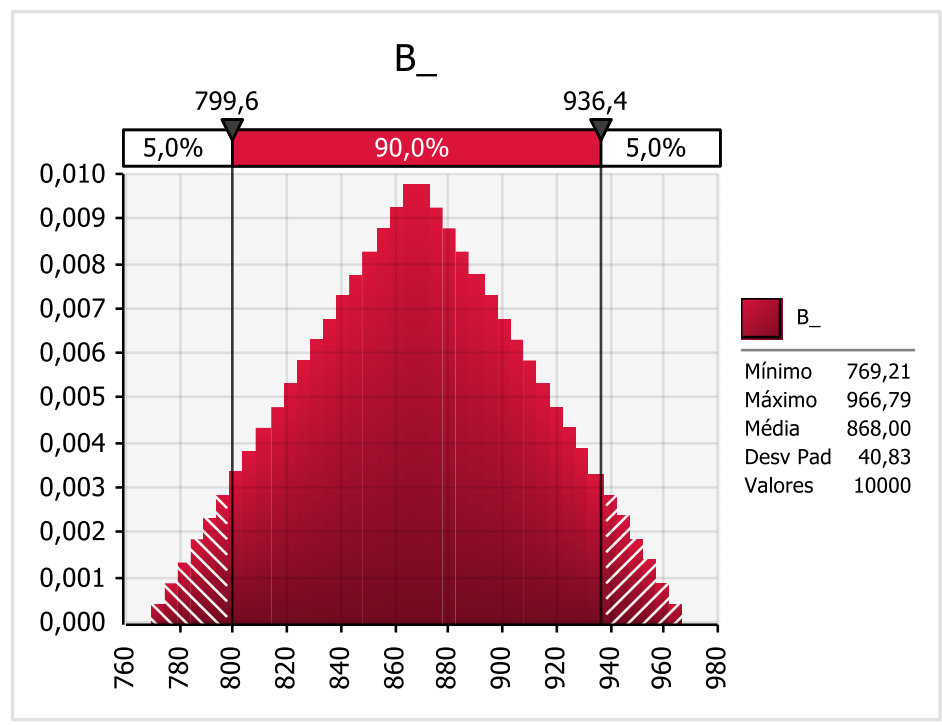

Figura 9 - Distribuição de probabilidade de ocorrência para a variável volume da reserva

Fonte: Elaboração própria no @ Risk 


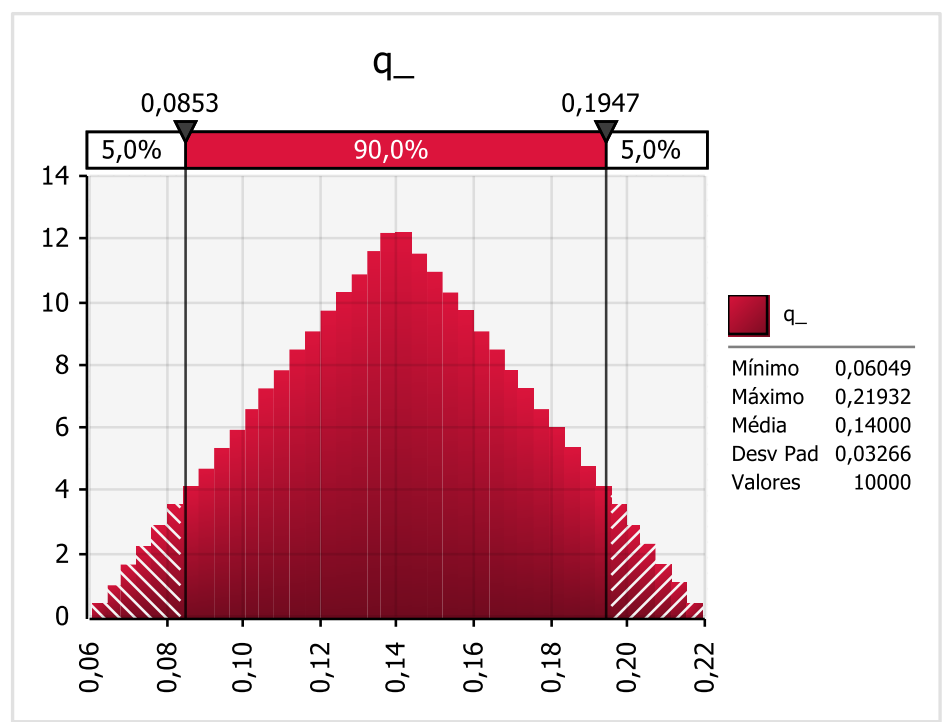

Figura 10 - Distribuição de probabilidade de ocorrência para a variável qualidade da reserva

Fonte: Elaboração própria no @Risk

Como o investimento é uma função linear que varia com o volume da reserva, seu gráfico também segue uma distribuição triangular.

Com os valores simulados de $P, B$ e q', foi calculado o valor presente do projeto neutro ao risco, através da fórmula $V=\left(q^{*} B^{*} P\right)-C$, onde o custo operacional (C) é fixo.

Após achar os valores do investimento e do valor presente do projeto neutro ao risco, foram calculados os valores de $V^{\prime}$ e $I^{\prime}$, ao somar o custo operacional. Estes são os valores usados no cálculo da opção americana, através da aproximação analítica de Bjerksund e Stensland.

O gráfico da Figura 11 mostra o resultado do valor da opção em $t=1$, que expira em $t=2$. Note que o valor da opção não assume valores negativos. Nos casos onde o VLP é negativo ou muito pequeno, temos a opção de não investir. Como a premissa deste estudo é revelação da informação perfeita das incertezas técnicas, se após a realização do TLD, o $q$ ' e $B$ revelados não tiverem VPL positivo, não será feito o desenvolvimento do campo. Se o VPL for positivo, porém menor que o valor de espera, o valor da opção real será maior que o VPL de exercício e o ótimo é esperar. 


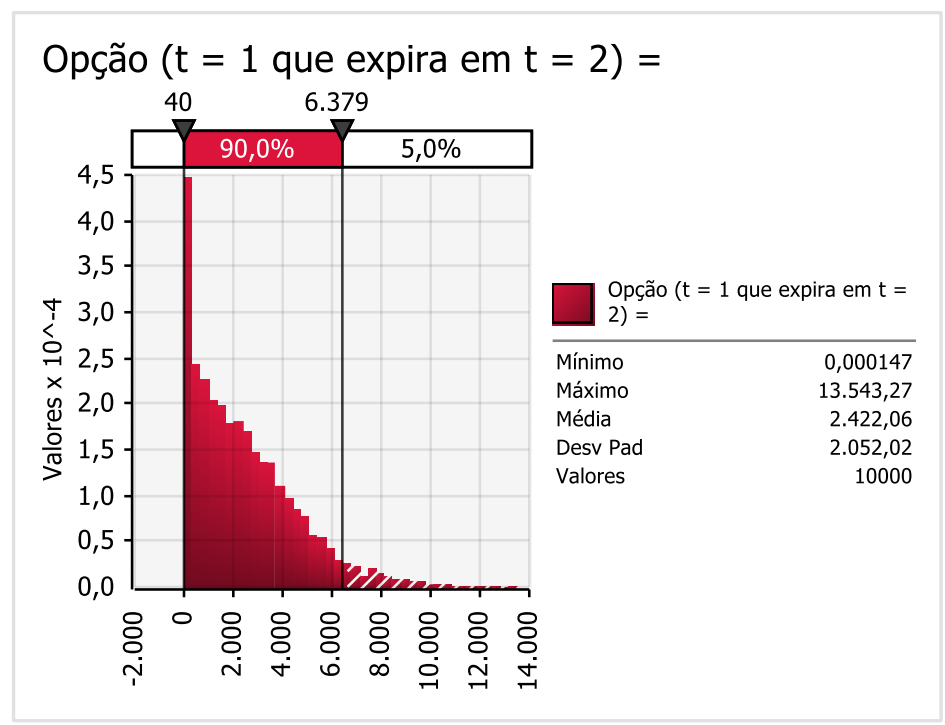

Figura 11 - Distribuição de probabilidade de ocorrência da opção em t=1.

Fonte: Elaboração própria no @ Risk

Como a distribuição dos valores da opção foi calculada para $t=1$, foi necessário trazer para $t=0$, já que, depois de abatido o custo da informação, foi comparado com o VLP do projeto sem informação. Sendo assim, o gráfico com os valores da opção trazido para $t=0$ é apresentado na Figura 12.

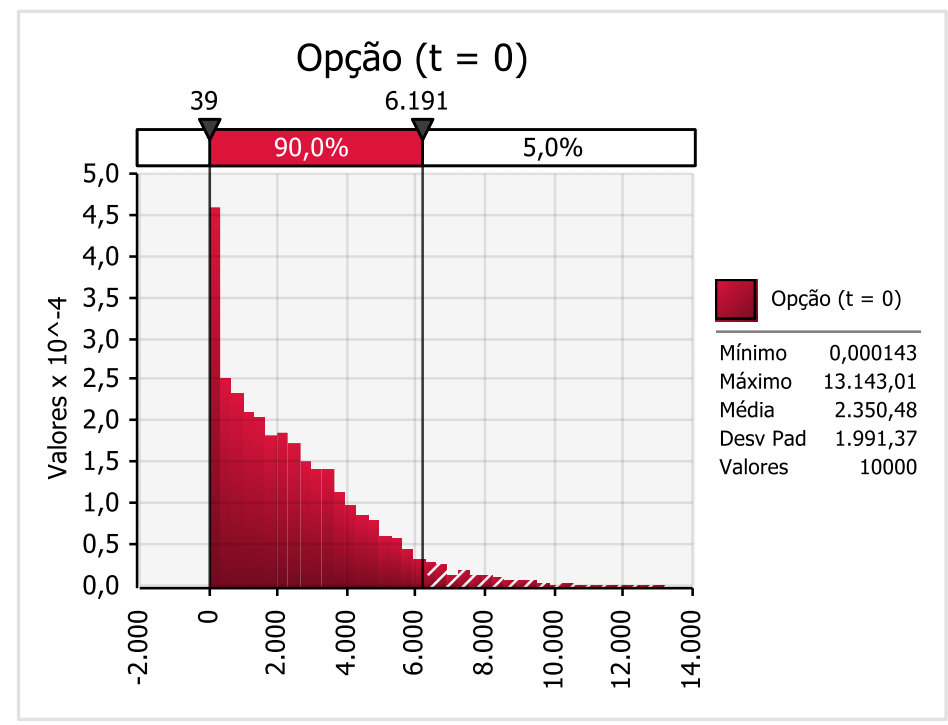

Figura 12 - Distribuição de probabilidade de ocorrência da opção em t=0

Fonte: Elaboração própria no @Risk

Como já mencionado, além de trazer os valores da opção para o valor presente, o custo do investimento em informação foi descontado com o objetivo de comparar com o VPL do projeto sem informação. 
O gráfico da Figura 13 apresenta o valor final deste cenário. Para efeito comparativo, foi usado o valor médio da distribuição de VPL, que, conforme o gráfico, é US\$2.250,48 milhões.

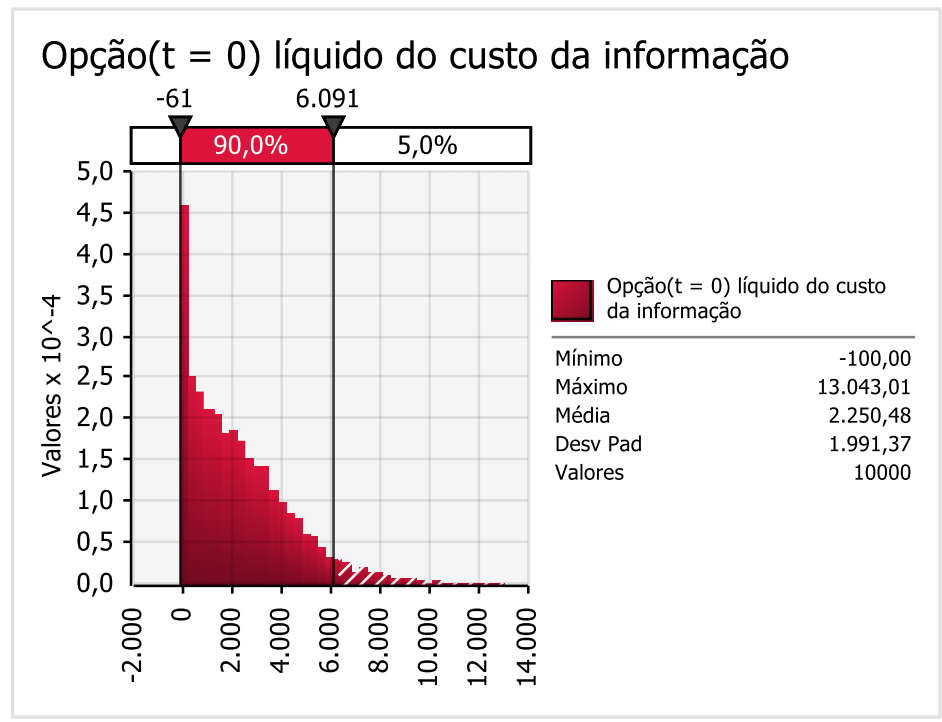

Figura 13 - Distribuição de probabilidade de ocorrência da opção em t=0 e líquido do custo de investimento em informação

Fonte: Elaboração própria no @ Risk

O valor médio apresentado no gráfico acima, é o valor do VPL do projeto, investindo em informação, em $t=0$. Este valor deve ser comparado com o valor do VPL do projeto sem investir em informação e o cenário que apresentar maior VPL deve ser escolhido.

Então, o próximo passo foi calcular o VPL do projeto sem informação. Este VPL foi calculado considerando o valor do preço do petróleo em $t=0$ e o valor do investimento com base no valor esperado do volume da reserva $(B)$.

Foi aplicado o fator de restrição $(\gamma)$ toda vez que o valor da simulação de $q^{\prime *} B$ fosse maior que o valor esperado, $E\left[q^{\prime}\right]^{*} E[B]$, penalizando seu VLP. Isso se deve à restrição da capacidade de produção. Como o investimento foi feito com base no valor esperado de B, a escolha da UEP foi errada e menor que o potencial do campo, limitando a produção/receita e consequente perda de VPL.

No caso contrário, onde $q^{\prime * B}$ fosse menor que $E\left[q^{\prime}\right]^{*} E[B]$, o VPL sem informação também foi penalizado, pois foi feito um investimento maior (escolha de uma UEP maior) que o necessário, baseado no valor esperado de $B$. 


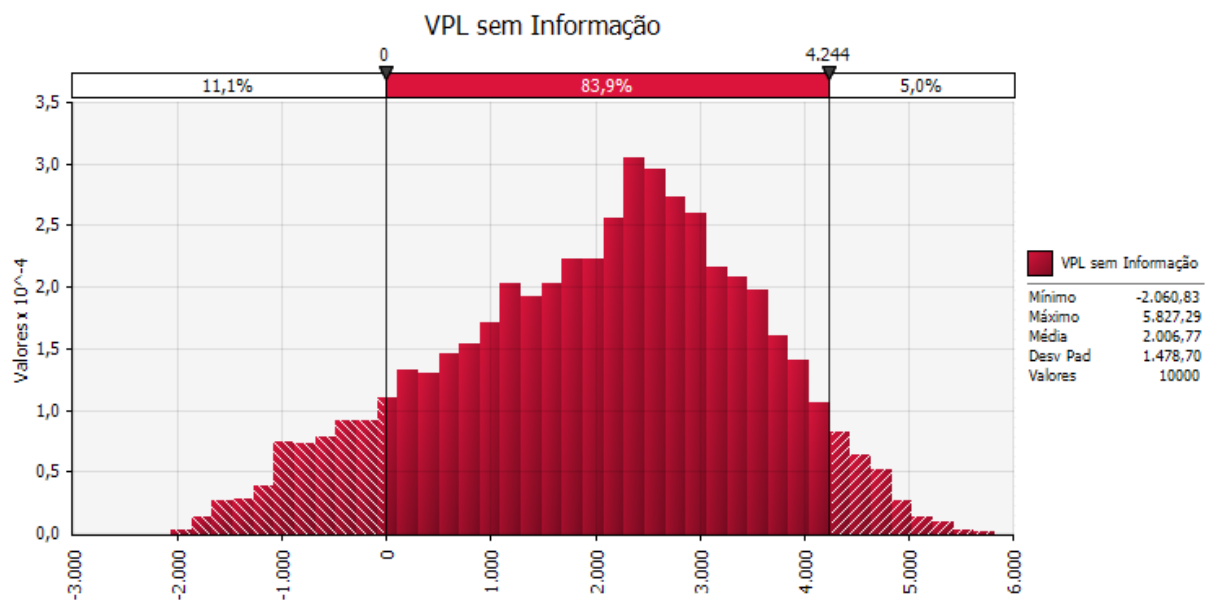

Figura 14 - Distribuição de probabilidade de ocorrência do VPL sem informação Fonte: Elaboração própria no @ Risk

Na média, o VPL foi positivo e igual a US\$ 2.006,77 milhões. Pode ser observado também que em aproximadamente $11,1 \%$ dos casos, o VPL é negativo, ou seja, a escolha do investimento pode ter sido a escolha errada.

Comparando o valor médio da OR com informação, líquido do custo da informação, com o VPL sem a informação é possível concluir que vale mais a pena, neste caso, investir em informação e ter a revelação perfeita dos dados de reservatório e assim ter a opção de investir ou não no projeto. A diferença de VPL foi de US\$243,71 milhões neste estudo de caso.

Tabela 2 - Comparativo de valores

\begin{tabular}{|c|c|}
\cline { 2 - 2 } \multicolumn{1}{c|}{} & Valores em $\mathbf{t}=\mathbf{0}$ (em US\$ MM) \\
\hline OR com informação & 2250,48 \\
\hline VPL sem informação & 2006,77 \\
\hline UVPL & $\mathbf{2 4 3 , 7 1}$ \\
\hline
\end{tabular}

Fonte: Elaboração própria

\subsection{Análise de Sensibilidade}

Após rodar o caso base, foi feita uma análise de sensibilidade em cima de determinados parâmetros, foram eles: custo da informação, fator de restrição $(\gamma)$, custo operacional, volatilidade, taxa livre de risco e taxa de conveniência. Ao variar 
os valores de um parâmetro, todos os outros foram mantidos constantes, com o objetivo de verificar o qual impacto o parâmetro tinha no VPL do projeto.

\subsubsection{Custo da Informação}

O custo da informação inserido no modelo foi do custo de realização do Teste de Longa Duração. Ao variar o valor do custo da informação, apenas o valor da OR com informação varia. A pequena variação no VPL sem informação se deve às pequenas variações nas variáveis estocásticas a cada simulação. Quanto maior o custo da informação, menor a diferença entre os VPLs com e sem informação. Isso significa que a partir de um determinado valor para custo da informação, este investimento não valerá mais a pena.

Tabela 3 - Variação do $\triangle$ VPL (em US\$ MM) com a variação do custo da informação (em US\$ MM).

\begin{tabular}{|c|c|c|c|}
\hline Custo da Informação & VPL sem Informação & OR com Informação & $\Delta$ VPL \\
\hline 70,00 & 2007,14 & 2279,47 & 272,33 \\
\hline 80,00 & 2006,64 & 2261,29 & 254,65 \\
\hline 90,00 & 2006,09 & 2256,09 & 250,00 \\
\hline 100,00 & $\mathbf{2 0 0 6 , 7 7}$ & $\mathbf{2 2 5 0 , 4 8}$ & $\mathbf{2 4 3 , 7 1}$ \\
\hline 110,00 & 2006,38 & 2233,35 & 226,97 \\
\hline 120,00 & 2006,74 & 2222,80 & 216,06 \\
\hline 130,00 & 2006,81 & 2215,68 & 208,87 \\
\hline \multicolumn{4}{|l}{} \\
\hline
\end{tabular}

Fonte: Elaboração própria

A Figura 15 apresenta os valores da tabela plotados num gráfico. Através dele, facilmente é observado que quanto maior o custo da informação, menor o $\triangle$ VPL. O valor onde a reta cruzar o eixo x é o valor a partir do qual não vale mais apena investir em informação. Neste estudo, este valor seria aproximadamente US\$ 330 milhões. 


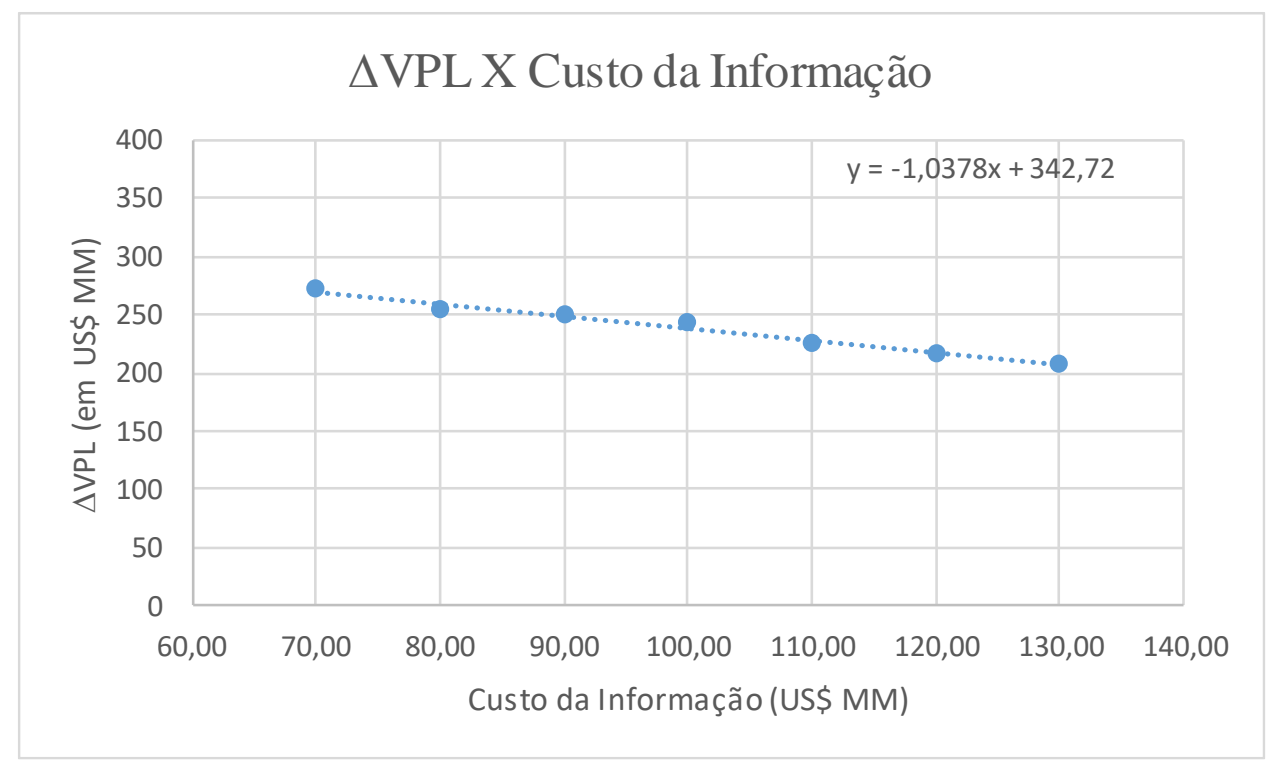

Figura 15- Variação do $\Delta$ VPL em função da variação do custo da informação

Fonte: Elaboração própria

\subsubsection{Fator de Restrição ( $\mathrm{Y}$ )}

O fator de restrição é um fator de penalização do VPL sem informação quando o valor de $q^{*} B$ (cenário revelado após o investimento em informação) é maior que o $E\left[q^{\prime}\right]^{*} E[B]$. Isso ocorre, pois caso o reservatório tenha um potencial de produção real maior que a estimativa sem informação, a capacidade de UEP escolhida não terá sido a capacidade ótima, restringindo a produção e, consequentemente, a receita, gerando uma perda de VPL.

A Tabela 4 mostra que quanto menor este fator de restrição, maior a penalização do VPL sem informação, aumentando assim o $\Delta$ VPL. Note que a penalização ocorre apenas no caso sem informação, já que a revelação da informação neste estudo de caso é perfeita. A pequena variação no valor da OR com informação se deve às pequenas variações nas variáveis estocásticas a cada simulação. 
Tabela 4 - Variação do $\Delta$ VPL (em US\$ MM) com a variação do fator de restrição

\begin{tabular}{|c|c|c|c|}
\hline Fator de Restrição (Y) & VPL sem Informação & OR com Informação & $\Delta$ VPL \\
\hline 0,49 & 1858,18 & 2246,03 & 387,85 \\
\hline 0,56 & 1907,96 & 2247,89 & 339,93 \\
\hline 0,63 & 1956,58 & 2252,94 & 296,36 \\
\hline 0,7 & 2006,77 & 2250,48 & 243,71 \\
\hline 0,77 & 2056,34 & 2250,50 & 194,16 \\
\hline 0,84 & 2105,78 & 2247,60 & 141,82 \\
\hline 0,91 & 2156,38 & 2246,32 & 89,94 \\
\hline \multicolumn{3}{|c}{} \\
\hline
\end{tabular}

Fonte: Elaboração própria

Quando não houver restrição da capacidade este fator é igual a 1. Se houver restrição este fator é menor que 1 e maior que zero. Quando o fator é igual a zero, a penalização é máxima.

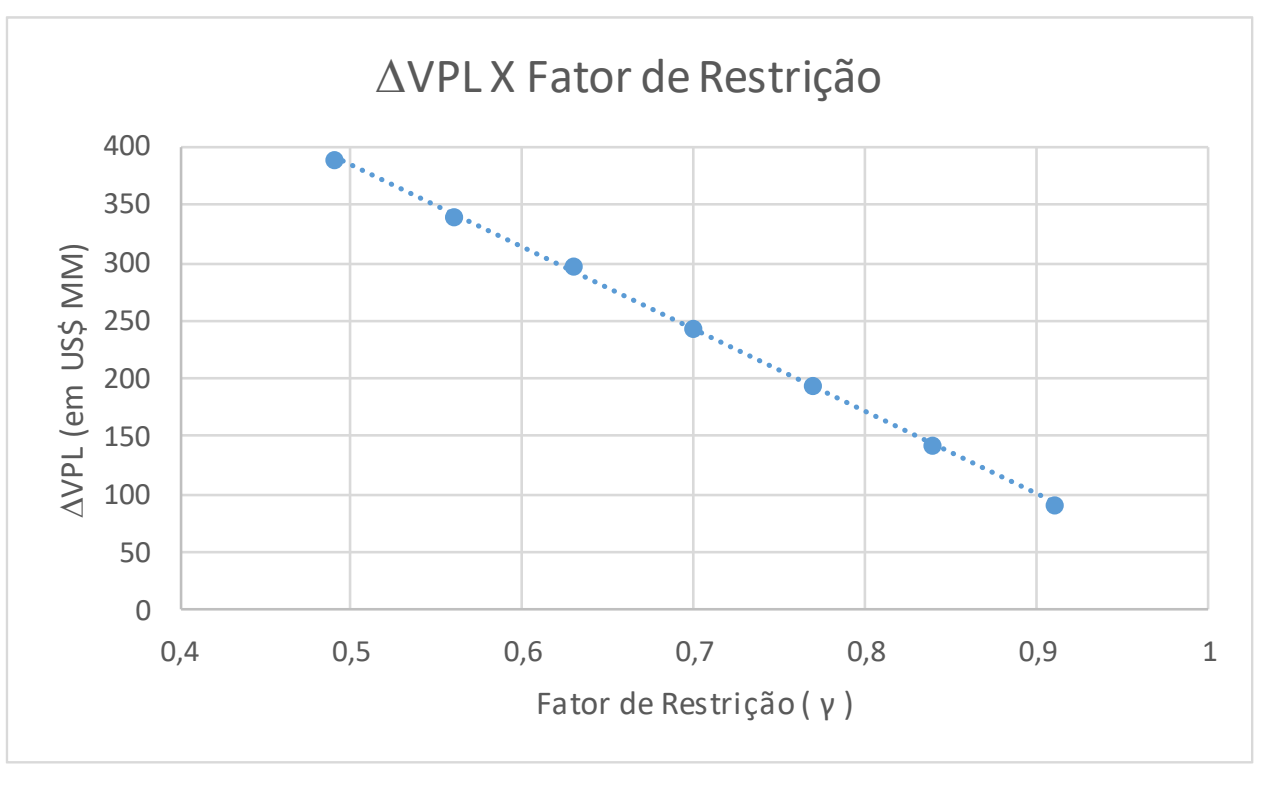

Figura 16 - Variação do $\Delta$ VPL em função do fator de restrição

Fonte: Elaboração própria

\subsubsection{Custo Operacional}

No modelo apresentado, o valor do custo operacional foi de US\$1.200,00 milhões. Este valor foi considerado fixo no modelo, porém pode ser visto como um custo com uma parcela fixa e outra variável a depender do volume da reserva $(B)$, como ocorre com o valor do investimento. 
Embora tenha sido considerado fixo, foi feita uma análise de sensibilidade para mostrar como o custo operacional pode afetar os resultados. Como este é um modelo de Fluxo de Caixa Rígido, o custo operacional é calculado por fora. Ele entra tanto no cálculo do valor da OR com informação, quanto no VPL sem informação, porém com intensidade diferente.

Tabela 5 - Variação do $\Delta$ VPL (em US\$ MM) com a variação do custo operacional (em US\$ MM)

\begin{tabular}{|c|c|c|c|}
\hline Custo Operacional & VPL sem Informação & OR com Informação & $\Delta$ VPL \\
\hline 840,00 & 2366 & 2535,70 & 169,35 \\
\hline 960,00 & 2247 & 2439,58 & 192,68 \\
\hline 1080,00 & 2127 & 2338,75 & 212,04 \\
\hline 1200,00 & 2007 & 2250,48 & 243,71 \\
\hline 1320,00 & 1886 & 2148,30 & 261,85 \\
\hline 1440,00 & 1766 & 2060,95 & 294,56 \\
\hline 1560,00 & 1646 & 1970,30 & 324,29 \\
\hline
\end{tabular}

Fonte: Elaboração própria

Como mostrado no gráfico da Figura 17, a alteração do custo operacional, com todos os outros parâmetros constantes, faz os dois VPLs alterarem. Quanto maior o custo operacional, menores ficam os VPLs. Pode ser observado também que o VPL sem informação sofre maior influência que o valor da OR com informação, fazendo com que a curva do VPL do primeiro tenha uma inclinação maior, aumentando assim o $\triangle$ VPL. 


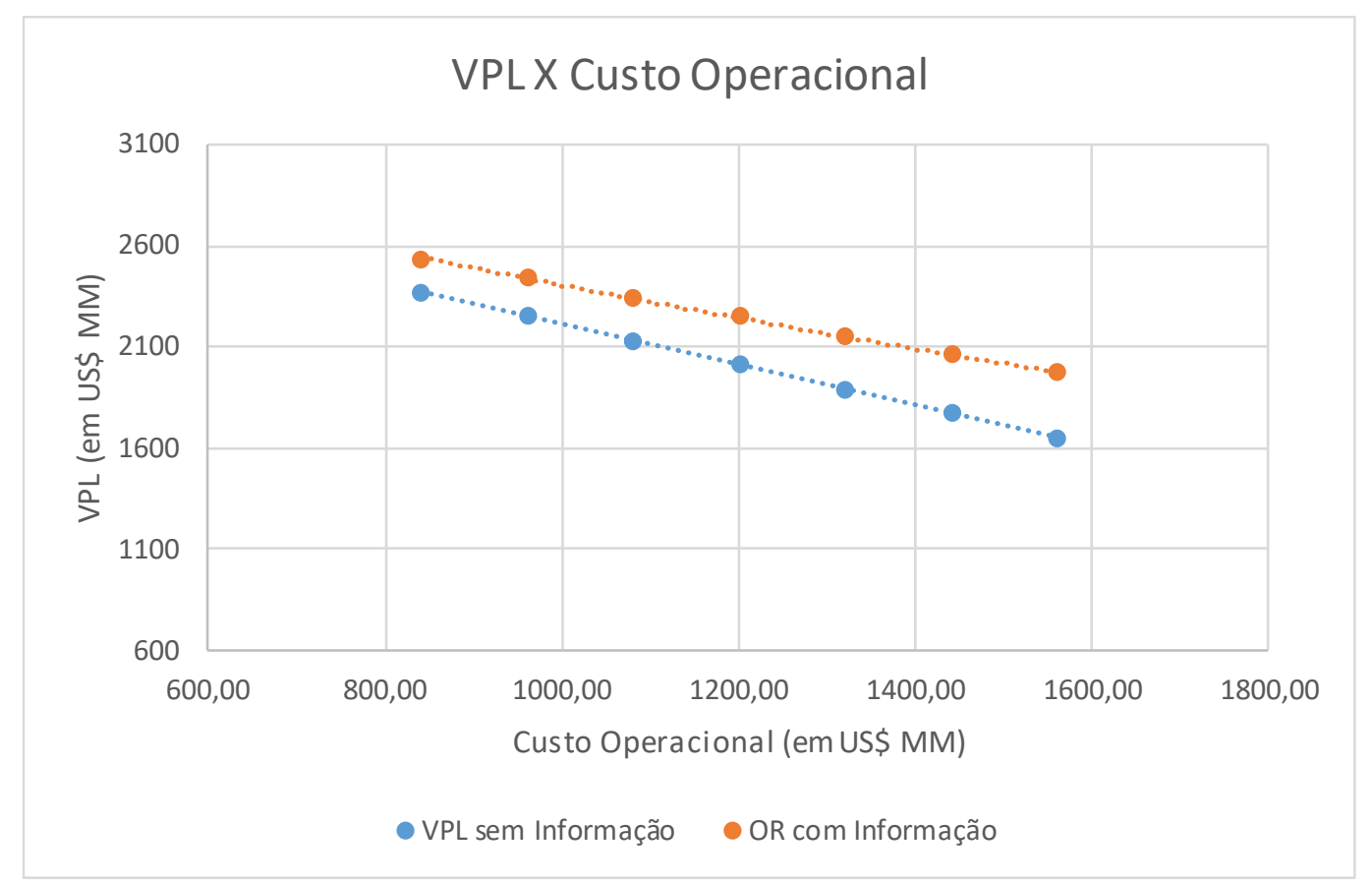

Figura 17- Variação dos VPLs (com e sem informação) em função do custo operacional

Fonte: Elaboração própria

\subsubsection{Volatilidade}

A volatilidade é um dos parâmetros necessários para o cálculo do valor da opção. Ela entra no cálculo do valor do preço futuro do petróleo e na fórmula da aproximação de aproximação analítica de Bjerksund e Stensland. No caso base foi utilizado o valor de $20 \%$. Foi realizado a variação da sensibilidade para entender de que forma os VPLs iriam se comportar. Como a volatilidade influencia apenas parâmetros do valor da OR com informação, apenas este sofre variação. Novamente, a pequena variação no VPL sem informação se deve às pequenas variações nas variáveis estocásticas a cada simulação. 
Tabela 6 - Variação do $\Delta$ VPL (em milhões de US\$) com a variação da volatilidade.

\begin{tabular}{|c|c|c|c|}
\hline Volatilidade $(\boldsymbol{\sigma})$ & VPL sem Informação & OR com Informação & $\Delta$ VPL \\
\hline $14,00 \%$ & 2006,30 & 2170,00 & 163,70 \\
\hline $16,00 \%$ & 2006,91 & 2188,75 & 181,84 \\
\hline $18,00 \%$ & 2006,60 & 2215,53 & 208,93 \\
\hline $\mathbf{2 0 , 0 0 \%}$ & $\mathbf{2 0 0 6 , 7 7}$ & $\mathbf{2 2 5 0 , 4 8}$ & $\mathbf{2 4 3 , 7 1}$ \\
\hline $22,00 \%$ & 2006,23 & 2278,42 & 272,19 \\
\hline $24,00 \%$ & 2006,61 & 2307,62 & 301,01 \\
\hline $26,00 \%$ & 2006,52 & 2336,14 & 329,62 \\
\hline
\end{tabular}

Fonte: Elaboração própria

Com o aumento da volatilidade, o valor da OR com informação aumenta também, conforme apresentado no gráfico da Figura 18. Esse comportamento é esperado conforme diferentes casos apresentados na literatura.

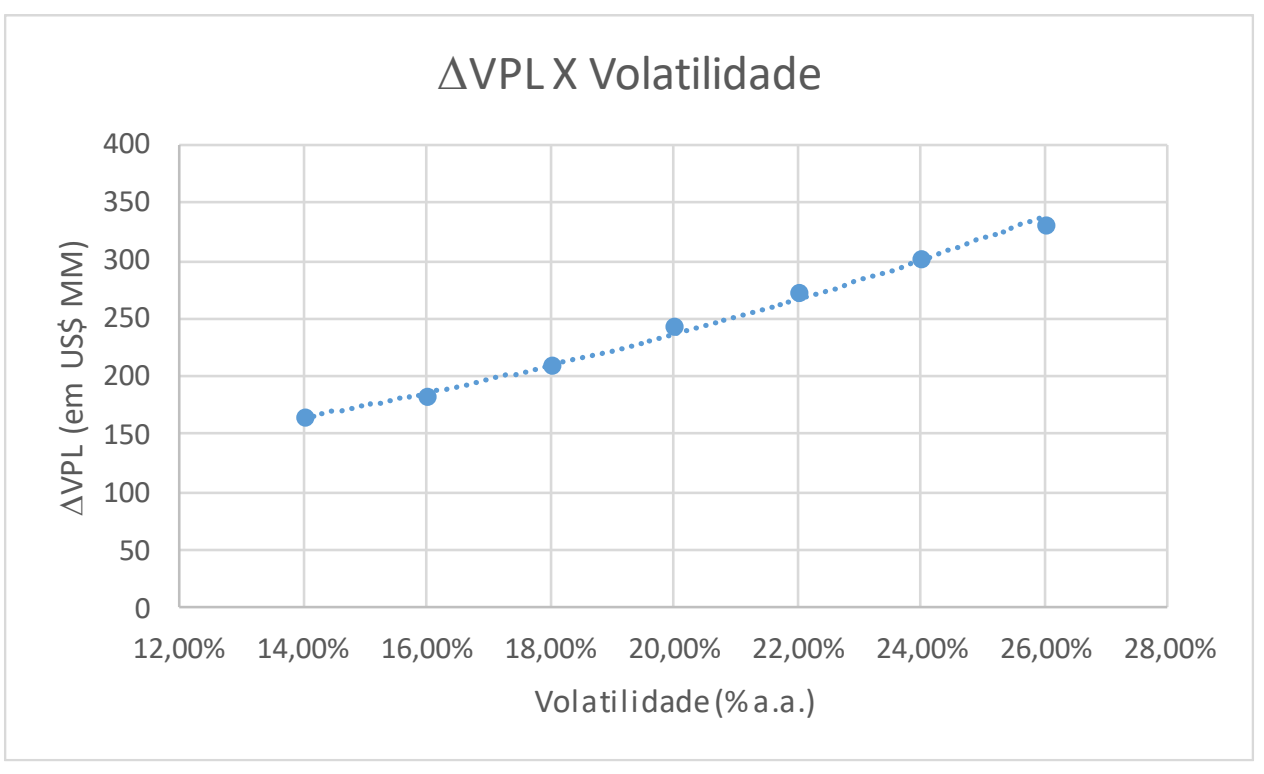

Figura 18 - Variação do $\Delta$ VPL em função da volatilidade

Fonte: Elaboração própria

\subsubsection{Taxa Livre de Risco}

A taxa livre de risco, como a volatilidade, entra no cálculo do valor do preço futuro do petróleo e na fórmula da aproximação de aproximação analítica de Bjerksund e Stensland. Atualmente no Brasil o seu valor nominal está próximo de $3 \%$ em termos reais. Mais uma vez, sua influência é apenas no valor da OR com 
informação e a pequena variação no VPL sem informação se deve às pequenas variações nas variáveis estocásticas a cada simulação.

Tabela 7 - Variação do $\Delta$ VPL (em US\$ MM) com a variação da taxa livre de risco

\begin{tabular}{|c|c|c|c|}
\hline Taxa Livre de Risco ( $\mathbf{~}$ ) & VPL sem Informação & OR com Informação & $\Delta$ VPL \\
\hline $2,10 \%$ & 2006,17 & 2202,99 & 196,82 \\
\hline $2,40 \%$ & 2007,39 & 2213,81 & 206,42 \\
\hline $2,70 \%$ & 2007,23 & 2226,92 & 219,69 \\
\hline $\mathbf{3 , 0 0 \%}$ & $\mathbf{2 0 0 6 , 7 7}$ & $\mathbf{2 2 5 0 , 4 8}$ & $\mathbf{2 4 3 , 7 1}$ \\
\hline $3,30 \%$ & 2006,91 & 2259,15 & 252,24 \\
\hline $3,60 \%$ & 2006,42 & 2276,86 & 270,44 \\
\hline $3,90 \%$ & 2007,45 & 2290,37 & 282,92 \\
\hline
\end{tabular}

Fonte: Elaboração própria

A taxa livre de risco possui o mesmo comportamento que a volatilidade, quanto maior seu valor, maior o valor da OR com informação, maior o $\Delta$ VPL.

\section{$\triangle$ VPLX Taxa Livre de Risco}

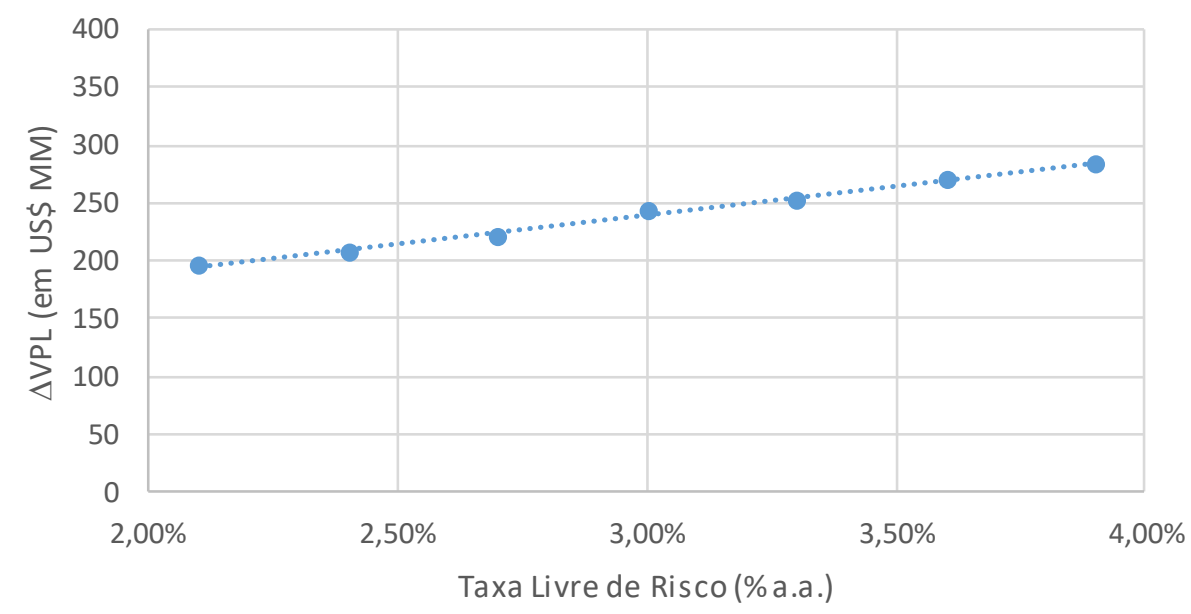

Figura 19 - Variação do $\Delta$ VPL em função da taxa livre de risco

Fonte: Elaboração própria

\subsubsection{Taxa de Conveniência}

Por último, foi feita a análise de sensibilidade da taxa de conveniência. Sua variação tem influência no valor da OR com informação, pois como a volatilidade e a taxa livre de risco, está no cálculo do valor do preço futuro do petróleo e na fórmula da aproximação analítica de Bjerksund e Stensland. A diferença é que ela 
varia no sentido oposto, ou seja, quanto maior seu valor, menor é o valor da OR com informação e menor o $\Delta$ VPL.

Tabela 8 - Variação do $\Delta$ VPL (em US\$ MM) com a variação da taxa de conveniência

\begin{tabular}{|c|c|c|c|}
\hline Taxa de Conveniência ( $\boldsymbol{\delta}$ ) & VPL sem Informação & OR com Informação & $\Delta$ VPL \\
\hline $2,10 \%$ & 2006,65 & 2316,77 & 310,12 \\
\hline $2,40 \%$ & 2006,67 & 2290,97 & 284,30 \\
\hline $2,70 \%$ & 2007,22 & 2273,29 & 266,07 \\
\hline $\mathbf{3 , 0 0 \%}$ & $\mathbf{2 0 0 6 , 7 7}$ & $\mathbf{2 2 5 0 , 4 8}$ & $\mathbf{2 4 3 , 7 1}$ \\
\hline $3,30 \%$ & 2007,04 & 2220,41 & 213,37 \\
\hline $3,60 \%$ & 2007,01 & 2200,22 & 193,21 \\
\hline $3,90 \%$ & 2007,67 & 2173,17 & 165,50 \\
\hline
\end{tabular}

Fonte: Elaboração própria

Pelo gráfico da Figura 20, é possível observar que a taxa de conveniência é inversamente proporcional ao $\triangle \mathrm{VPL}$. Quanto maior a taxa, menor é o valor do $\triangle$ VPL.

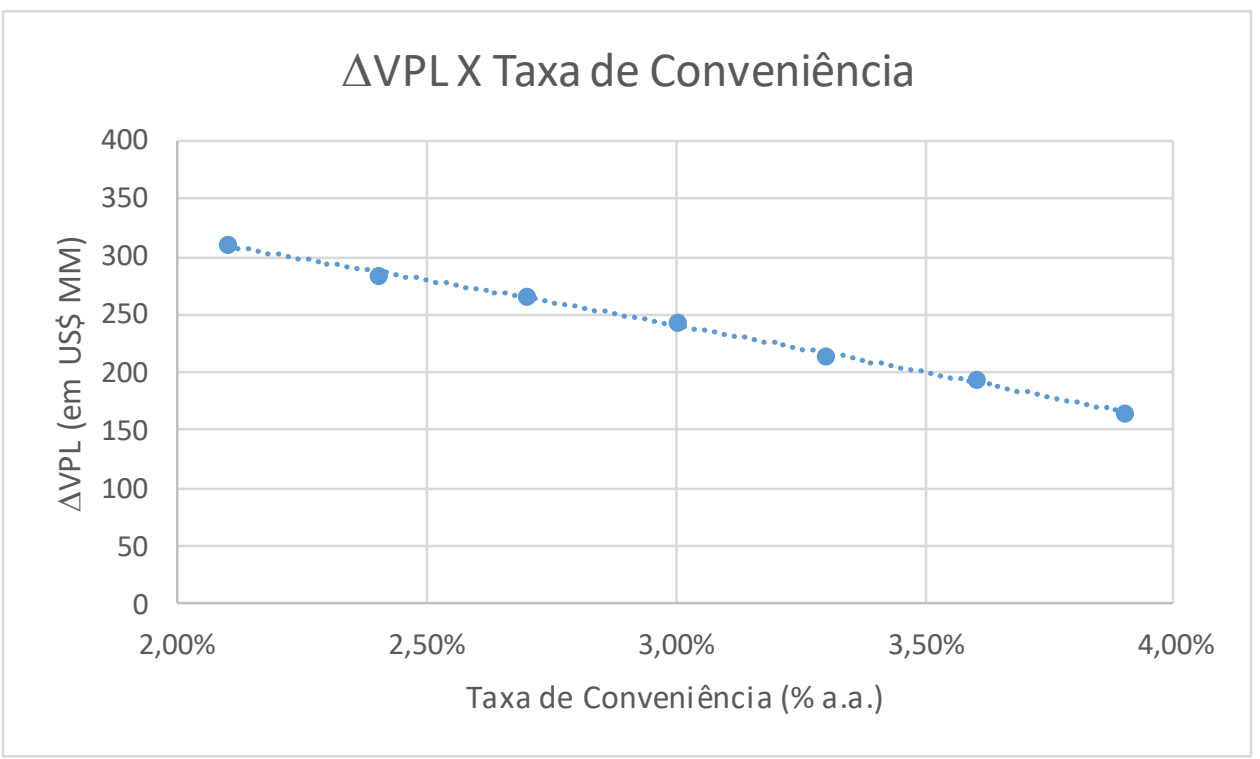

Figura 20 - Variação do $\Delta$ VPL em função da taxa de conveniência

Fonte: Elaboração própria

\subsubsection{Sensibilidade do $\triangle \mathrm{VPL}$}

Para efeito comparativo dos parâmetros na influência do $\Delta$ VPL foi feito um gráfico onde todos os parâmetros variam da seguinte forma: $-30 \%,-20 \%,-10 \%$, $10 \%, 20 \%$ e $30 \%$. 


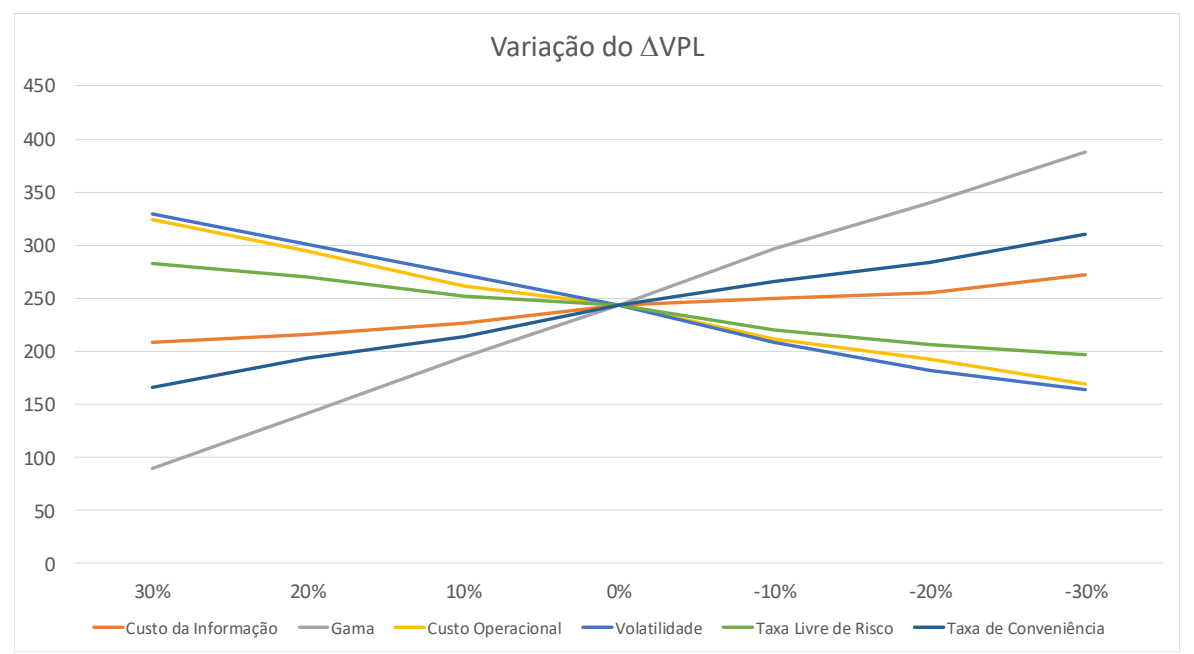

Figura 21 - Variação do $\Delta$ VPL em função da variação de cada parâmetro

Fonte: Elaboração própria

Com o gráfico da Figura 21, foi possível concluir que o parâmetro que mais impacta o $\triangle$ VPL com sua variação é o fator de restrição e o que menos impacta é o custo da informação, ou seja, dos parâmetros analisados, o $\Delta$ VPL é mais sensível ao fator de restrição e menos sensível ao custo da informação. 


\section{Conclusões}

O objetivo deste trabalho foi o de estudar o valor da opção de aprendizagem e espera aplicada a um campo de exploração e produção de petróleo. Foi realizada uma comparação entre o projeto sem investimento e com o investimento em informação. Sem o investimento em informação, o VPL não é otimizado, pois ele sempre será penalizado devido ao mal dimensionamento do projeto. Com o investimento em informação, e revelação da informação perfeita de reservatório, o projeto apresenta o VPL otimizado, porém nem sempre vale a pena, a depender dos dados e premissas do problema.

Neste estudo de caso, onde foram usados dados típicos do pré-sal brasileiro, verificou-se que o investimento em informação através da realização de um Teste de Longa Duração (TLD) agrega valor ao projeto. Como premissa, este investimento prévio gera valor ao eliminar as incertezas técnicas. Assim, os resultados apresentados indicam o upper bound ou limite superior, já que nos casos reais o investimento em informação reduz, e não elimina, estas incertezas.

Os resultados indicam que o VPL do projeto após o TLD ficou $12 \%$ acima do VPL do projeto sem investir em informação. O VPL sem informação foi de US\$ $2.006,77$ e o valor da OR com informação foi de US\$2.250,48. Esse aumento no VPL se deve ao fato do projeto, com informações perfeitas de reservatório, poder investir na UEP de tamanho adequado ao volume a ser produzido pelo campo. Caso contrário, o VPL é penalizado pelo mal dimensionamento, seja por gastar mais que o necessário numa UEP com capacidade acima do potencial de produção, seja por contratar uma UEP com capacidade menor que o necessário, restringindo a produção do campo.

A análise de sensibilidade mostrou o comportamento de cada parâmetro do problema com o objetivo de verificar o impacto delas no VPL do projeto, com e sem informação. O custo da informação influencia apenas o valor da OR com informação. Quanto maior o custo da informação, menor o valor da OR com informação. Pode-se ter uma ideia do custo da informação a partir do qual não se 
vale mais investir em informação. Neste estudo, com as premissas e dados de entrada do caso base, este valor seria de aproximadamente US\$ 330,00 milhões.

Outro parâmetro analisado foi o fator de restrição da UEP, que altera apenas o valor do VPL sem informação. Quanto menor o fator, maior a penalização no VPL. Quando o fator é igual a 0 a penalização é máxima e quando é igual a 1 não há penalização.

O custo operacional tem influência no resultado dos dois VPLs. Isso acontece, pois ele entra no cálculo tanto do VPL sem informação, quanto no valor da OR com informação. Quanto maior o custo operacional, menor o valor dos VPLs, porém o VPL sem informação sofre maior influência que o valor da OR com informação.

Por último, a volatilidade, a taxa livre de risco e a taxa de conveniência, estes três parâmetros estão presentes tanto no cálculo do valor do preço futuro do petróleo, quanto na fórmula da aproximação analítica de Bjerksund e Stensland. Dessa forma, apenas o valor da OR com informação é alterado com a variação deles. Quanto maior o valor da volatilidade ou da taxa livre de risco, maior o valor da OR com informação. Já a taxa de conveniência apresentado o comportamento inverso. Quanto maior o seu valor, menor o valor da OR com informação.

Foi possível concluir que o parâmetro que mais impacta o $\Delta$ VPL com sua variação é o fator de restrição e o que menos impacta é o custo da informação, ou seja, dos parâmetros analisados, o $\triangle \mathrm{VPL}$ é mais sensível ao fator de restrição e menos sensível ao custo da informação.

Este tipo de análise é importante, pois o resultado depende das premissas e dados de entrada no modelo, podendo tornar o investimento em informação desinteressante. Este estudo de caso foi elaborado com base em informações de projetos do pré-sal brasileiro com o objetivo de trazer o mais próximo à realidade.

Projetos que possuem jazidas estendendo-se para outro campo, precisam realizar a unitização e aprovar junto à ANP o Plano de Desenvolvimento (PD) da jazida compartilhada. Muitas vezes estes projetos são pressionados pelo prazo imposto pela ANP para a realização da unitização, mas é importante o entendimento da Agência que pode ser mais interessante conceder mais prazo para que o projeto 
estude as opções reais e realize o investimento em informação, caso se demonstre favorável ao projeto. A otimização do projeto é um benefício não só para as empresas responsáveis pelo desenvolvimento do campo, como também para o governo, que arrecada impostos como royalties e participação especial. Estes impostos são proporcionais à produção e à rentabilidade do campo de petróleo.

Uma sugestão para futuros trabalhos seria a avaliação da opção com modelo que gere informação incompleta, ou seja, a revelação parcial da informação, gerando distribuições a posteriori, com variância média menor que a distribuição a priori. A informação sempre irá reduzir incertezas e, consequentemente, a variância média das distribuições posteriores. 


\section{Referências bibliográficas}

ANP. Individualização da produção (ou unitização). Disponível em http://www.anp.gov.br, 2016. Acesso em: 25 de março de 2019

BJERKSUND, P.; STENSLAND, G. Closed form approximation of American options. Scandinavian Journal of Management, v. 9, p. S88-S99, 1993.

BJERKSUND, P; STENSLAND, G. Closed Form valuation of American options.

Department of Finance and Management Science, Bergen, Norway, 2002.

BLACK, F.; SCHOLES, M. The pricing of options and corporate liabilities. Journal of Political Economy, v.81, n.3, p.637-654, 1973.

BRAGA, L.P.; DAVID, O.B. Why the unitization process is an important issue when dealing with the Brazilian Pre-salt Polygon. Journal of World Energy Law and Business, v. 0, p.1-17, 2018.

BRANDÃO, E. T. Uma aplicação da teoria das opções reais em tempo discreto para avaliação de uma concessão rodoviária no Brasil. Rio de Janeiro, 2002. 132f. Tese de Doutorado. Departamento de Engenharia Industrial, Pontifícia Universidade Católica do Rio de Janeiro.

CEMIN JR, A.; MALISKA, C. R.; CORDAZZO, J. Aspectos sobre o cálculo de transmissibilidades em malhas formadas por contatos parciais. II Congresso Brasileiro de P\&D em Petróleo e Gás, 2003.

CHORN, L. G. et al. Resolving reservoir uncertainty to create value. In: SPE Annual Technical Conference and Exhibition. Society of Petroleum Engineers, 1998.

COELHO, A. A.; SUSLICK, S. B. Um Indicador do Valor da Informação Sísmica em Projetos de Exploração de Petróleo. In: 9th International Congress of the Brazilian Geophysical Society. 2005.

DEZEN, F; MOROOKA C. Field development decision making under uncertainty: A real option valuation approach. In: SPE Latin American and Caribbean Petroleum Engineering Conference. Society of Petroleum Engineers, 2001.

DIAS, M. A. G. Investimento sob incerteza em exploração \& produção de petróleo. Rio de Janeiro, 1996. 470p. Dissertação de Mestrado. Departamento de Engenharia Industrial, Pontifícia Universidade Católica do Rio de Janeiro. 
DIAS, M. A. G. Investment in information in petroleum, real options and revelation. In: Proceedings of the 6th Annual International Conference on Real Options. Real Options Group at Cyprus, Cyprus. 2002.

DIAS, M.A.G.; TEIXEIRA, J.P.; ROCHA, K.M.C. The Optimal Investment Scale and Timing: A Real Option Approach to Oilfield Development. In: 8th Annual International Conference on Real Options, 2004

DIAS, M.A.G. Opções reais híbridas com aplicação em petróleo. Rio de Janeiro, 2005. 490f. Tese de Doutorado. Departamento de Engenharia Industrial, Pontifícia Universidade Católica do Rio de Janeiro.

DIAS. M. A. G. Análise de Investimentos com opções reais - teoria e prática com aplicações em petróleo e em outros setores - Volume 1: conceitos básicos e opções reais em tempo discreto. Editora Brochura, Rio de Janeiro, 2014.

DIAS. M. A. G. Análise de Investimentos com opções reais - teoria e prática com aplicações em petróleo e em outros setores - Volume 2: processos estocásticos e opções reais em tempo contínuo. Editora Brochura, Rio de Janeiro, 2015.

DIXIT, A. K.; PINDYCK, R.S. Investment under uncertainty. Princeton University Press, Princeton, N.J., 1994.

EGBA, A. N. et al. Case Study of Unitisation and Joint Development of Straddle Fields in Nigeria. In: SPE Nigeria Annual International Conference and Exhibition. Society of Petroleum Engineers, 2016.

GUEDES, J.; SANTOS, P. Valuing an offshore oil exploration and production project through real options analysis. Energy Economics, v. 60, p. 377-386, 2016. LIMA, G. A. C. et al. A Real Options Model for Portfolio Selection of Oil and Gas Assets. In: SPE Annual Technical Conference and Exhibition. Society of Petroleum Engineers, 2002.

MA, M. Exploration Decision-Making on Energy Based On Improved Real Option Model and BP Neural Networks. International Journal of Control and Automation, v. 9, n. 10, p. 393-402, 2016.

MARQUES, E. Caracterização de Reservatórios Petrolíferos: Análise comparativa de dois métodos para a caracterização de propriedades de um reservatório petrolífero. 2011. 99f. 2011. Tese de Doutorado. Dissertação-Universidade Técnica de Lisboa. Lisboa.

MARTINI, R. F.; SCHIOZER, D. J.; NAKAJIMA, L. Use of quality maps in reservoir management. Journal of the Brazilian Society of Mechanical Sciences and Engineering, v. 27, n. 4, p. 463-468, 2005. 
MERTON, R. Theory of rational option pricing. Bell Journal of Economics and Management Science, v.4, n.1, p.141-183, 1973.

MYERS, S.; Determinants of corporate borrowing. Journal of Financial Economics, v.5, p. 147-175, 1977.

OZORIO, L. M. Opções reais na siderurgia: o caso brasileiro. Rio de Janeiro, 2011.

Tese de Doutorado. Departamento de Engenharia Industrial, Pontifícia Universidade Católica do Rio de Janeiro.

PADDOCK, J. L.; SIEGEL, D. R.; SMITH, J. L. Option valuation of claims on real assets: The Case of Offshore Petroleum Leases. Quarterly Journal of Economics, v. 103, n.3, p.479-508, 1988.

PICKLES, E.; SMITH, J.L. Petroleum Property Evaluation: A Binomial Lattice Implementation of Option Pricing Theory. Energy Journal, v.14, n. 2, p.126, 1993.

PETROBRAS. Conheça os diferentes tipos de poços de petróleo e gás natural. Disponível em http://www.petrobras.com.br, 2015. Acesso em: 12 de fevereiro de 2019.

PRÉ-SAL PETRÓLEO. Unitização. Disponível em http://www.presalpetroleo.gov.br, 2017. Acesso em: 25 de março de 2019.

SANTOS, J; M. D. Estudo da influência da estratégia de produção em análise de risco aplicada ao desenvolvimento de campos de petróleo. 2002.

SILVA, P. T. C.; Estudo de alternativas de arranjos submarinos de produção com uso de manifolds e bombas multifásicas: otimização da vazão e análise financeira. 2015. Tese de Doutorado. Universidade Federal do Rio de Janeiro.

TRIGEORGIS, L.; The Nature of Option Interactions and the Valuation of Investments with Multiple Real Options. Journal of Financial and Quantitative Analysis, p. 1-20, mar. 1993a.

TRIGEORGIS, L. et al.; Real options: Managerial flexibility and strategy in resource allocation. MIT press, 1996.

WORTHINGTON, Paul F. Provision for expert determination in the unitization of straddling petroleum accumulations. The Journal of World Energy Law \& Business, v. 9, n. 4, p. 254-268, 2016.

YOKOTA, Fumie; THOMPSON, Kimberly M. Value of information analysis in environmental health risk management decisions: past, present, and future. Risk analysis: an international journal, v. 24, n. 3, p. 635-650, 2004. 